\title{
Thermally dominated deep mantle LLSVPs: A review
}

\author{
D. R. Davies ${ }^{1 *}$, S. Goes ${ }^{2}$ and H. C. P. Lau ${ }^{2,3}$ \\ 1 Research School of Earth Sciences, The Australian National University, Canberra, ACT, Australia. \\ ${ }^{2}$ Department of Earth Sciences \& Engineering, Imperial College London, UK. \\ ${ }^{3}$ Department of Earth \& Planetary Sciences, Harvard University, Cambridge, MA, USA.
}

\begin{abstract}
The two large low shear-wave velocity provinces (LLSVPs) that dominate lower-mantle structure may hold key information on Earth's thermal and chemical evolution. It is generally accepted that these provinces are hotter than background mantle and are likely the main source of mantle plumes. Increasingly, it is also proposed that they hold a dense (primitive and/or recycled) compositional component. The principle evidence that LLSVPs may represent thermo-chemical 'piles' comes from seismic constraints, including: (i) their long-wavelength nature; (ii) sharp gradients in shear-wave velocity at their margins; (iii) non-Gaussian distributions of deep mantle shear-wave velocity anomalies; (iv) anti-correlated shear-wave and bulk-sound velocity anomalies (and elevated ratios between shear- and compressional-wave velocity anomalies); (v) anti-correlated shear-wave and density anomalies; and (vi) 1-D/radial profiles of seismic velocity that deviate from those expected for an isochemical, well-mixed mantle. In addition, it has been proposed that hotspots and the reconstructed eruption sites of large igneous provinces correlate in location with LLSVP margins. In this paper, we review recent results which indicate that the majority of these constraints do not require thermo-chemical piles: they are equally well (or poorly) explained by thermal heterogeneity alone. Our analyses and conclusions are largely based on comparisons between imaged seismic structure and synthetic seismic structures from a set of thermal and thermo-chemical mantle convection models, which are constrained by $\sim 300$ Myr of plate motion histories. Modelled physical structure (temperature, pressure and composition) is converted into seismic velocities via a thermodynamic approach that accounts for elastic, anelastic and phase contributions and, subsequently, a tomographic resolution filter is applied to account for the damping and geographic bias inherent to seismic imaging. Our results indicate that, in terms of large-scale seismic structure and dynamics, these two provinces are predominantly thermal features and, accordingly, that chemical heterogeneity is largely a passive component of lowermost mantle dynamics.
\end{abstract}

\section{Introduction}

2 The nature of two large low shear-wave velocity provinces (LLSVPs) in the deep mantle beneath Africa and 3 the South-Central Pacific (Fig. 1) has puzzled Earth scientists since they were first imaged in whole-mantle 4 tomography models over 30 years ago (e.g. Dziewonski et al., 1977; Woodhouse and Dziewonski, 1989). ${ }_{5}$ These LLSVPs cover $\sim 20 \%$ of the core-mantle-boundary (CMB) and extend up to $\sim 1000 \mathrm{~km}$ above the 6 CMB. They are particularly prominent in $S$-velocity sensitive data, with a weaker expression in $P$ data (e.g.

7 Woodhouse and Dziewonski, 1989; Ishii and Tromp, 1999; Masters et al., 2000; Hernlund and Houser, 2008), 8 hence their designation as low shear-wave velocity provinces.

*Correspondence to: rhodri.davies@anu.edu.au 

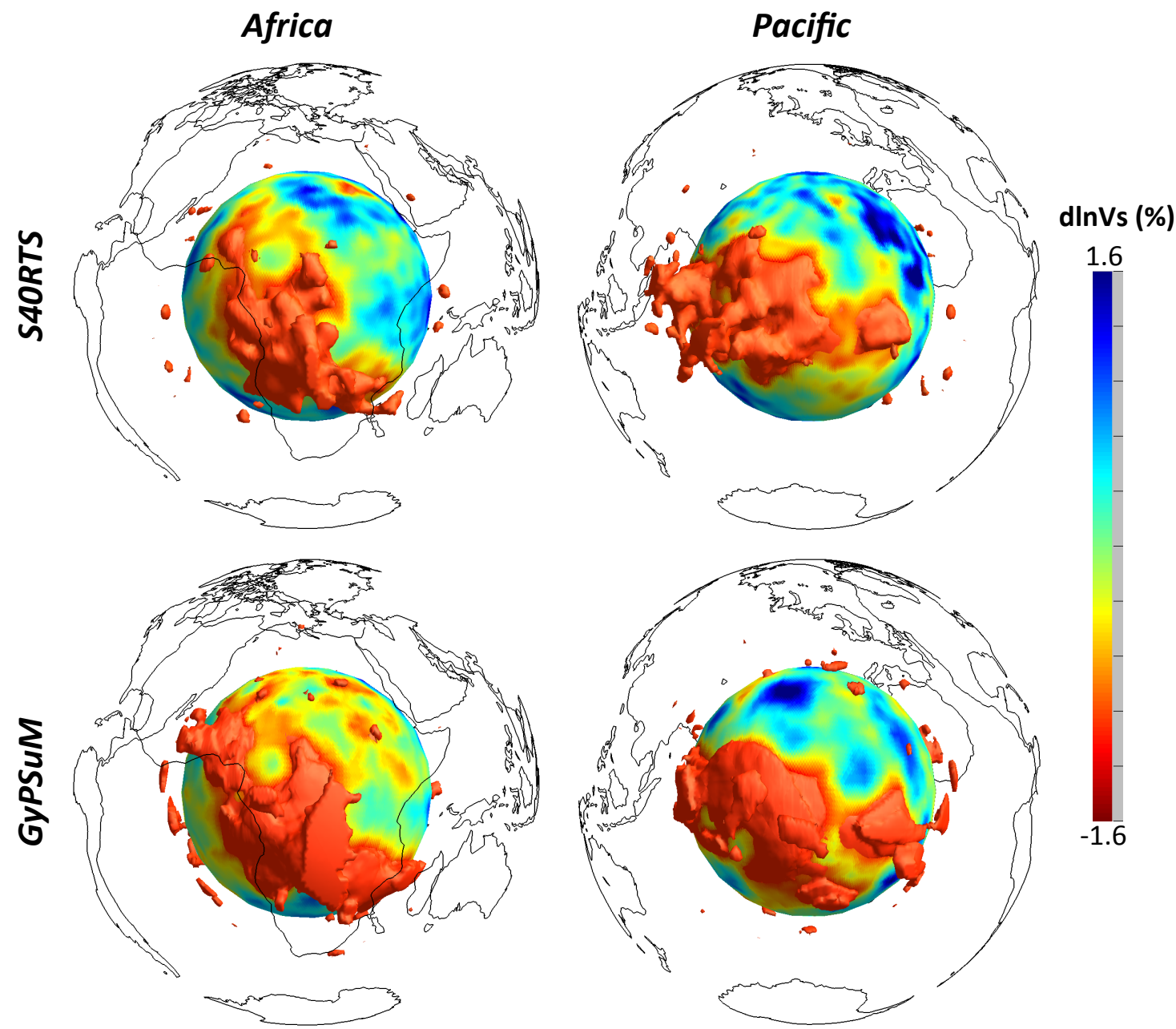

Figure 1: 3-D perspective of LLSVPs, outlined by shear-wave velocity perturbations beneath (left) Africa and (right) the Pacific, from tomographic models (top) S40RTS (Ritsema et al., 2011) and (bottom) GyPSum (Simmons et al., 2010). Each subfigure includes a radial surface at $2800 \mathrm{~km}$ depth and an isosurface at $-0.9 \%$ (S40RTS) / -1.0\% (GyPSum), clipped 1200 $\mathrm{km}$ above the CMB to allow for visualisation of lower-mantle features. Continental boundaries provide geographic reference.

There is a clear correlation between LLSVPs and: (i) the distribution of hotspots and the reconstructed eruptions sites of large igneous provinces (LIPs) and kimberlites (e.g. Duncan and Richards, 1991; Thorne et al., 2004; Torsvik et al., 2006; Burke et al., 2008; Torsvik et al., 2010; Austermann et al., 2014); and (ii) long-wavelength geoid highs (e.g. Anderson, 1982; Hager et al., 1985); indicating that these provinces are most likely hot and have a net positive buoyancy relative to the surrounding mantle (e.g., Gurnis et al., 2000; Forte and Mitrovica, 2001). Furthermore, there is a strong correlation between surrounding high seismic velocity material and former subduction zones (e.g. Richards and Engebretson, 1992; Bunge et al., 2002), whilst the long-wavelength geoid signature can be successfully reproduced by models where geoid highs result from a concentration of hot upwelling mantle away from ancient slabs (e.g. Ricard et al., 1993).

However, increasingly, arguments are being made that these provinces are not purely thermal features but contain a significant component of chemically dense material (see, for example, review by Garnero and 
McNamara, 2008). This material is proposed to be either sequestered from early in Earth's history (e.g. Allègre et al., 1987; Trieloff et al., 2000; Boyet and Carlson, 2006; Labrosse et al., 2007; Jackson et al., 2010; Jackson and Carlson, 2011; Deschamps et al., 2011), or predominantly composed of recycled oceanic

lithosphere (e.g. Christensen and Hofmann, 1994; Coltice and Ricard, 1999; Tackley et al., 2005; Brandenburg et al., 2008; Rapp et al., 2008). Arguments for such a compositional contribution come from geochemistry, mantle dynamics and, in particular, from seismology.

In this paper, we will review this evidence and demonstrate that the seismic observations do not require a substantial role for dense material in dictating the form of lower-mantle dynamics and its long-wavelength seismic expression. This does not imply the mantle is isochemical. Plate tectonics introduces mantle heterogeneity and a wealth of geochemical and geological data provide clear evidence for a heterogeneous mantle in major- and trace-element composition (e.g. Hofmann, 1997, 2003; Davies, 2011). Rather, it implies that chemical heterogeneity is largely a passive component of lower-mantle dynamics (i.e. its effect on density is outweighed by, or is secondary to, the effect of temperature), and that the seismic expression of LLSVPs is likely dominated by thermal effects.

\section{Background}

\subsection{Key geochemical constraints on mantle structure}

Geochemical observations offer important constraints on the nature of compositional heterogeneity within Earth's mantle (e.g. Wasserburg and De Paolo, 1979; Allègre et al., 1980; Zindler and Hart, 1986; Allègre et al., 1996; Hofmann, 1997, 2003; Boyet and Carlson, 2005; Tackley, 2007; Jackson and Carlson, 2011), with key observations including: (i) Lavas sampled at the two main sites of mantle upwelling on Earth, mid-ocean-ridge basalts (MORBs) and ocean-island basalts (OIBs), are chemically distinct, with MORBs generally more depleted in incompatible elements and somewhat less heterogeneous than OIBs, and OIBs requiring several different mantle source compositions (e.g. Hofmann, 1997, 2003); (ii) The isotopic ratios recorded in certain OIBs (and, occasionally, MORBs) require that some material recycled from the surface remains sequestered from the melt zone for several billion years (e.g. Zindler and Hart, 1986; Hofmann, 1997, 2003); and (iii) Recent measurements of lead and helium isotopic ratios from a number of flood basalt provinces imply that other material has remained sequestered within Earth's mantle for $\sim 4.5$ billion years (see Hanan and Graham, 1996; Jackson et al., 2010; Jackson and Carlson, 2011, and references therein). This signature is observed on Baffin Island and the Ontong Java Plateau and likely exists for six of the largest recorded volcanic events over the past $250 \mathrm{Myr}$, implying that its source must be reasonably wide-spread. Mass-balance calculations have been used to argue that this heterogeneity requires the existence of 
51

large-scale reservoirs that differ in both depth and composition. Classical methods of estimating the Bulk Silicate Earth's net composition (BSE - the mantle before extraction of the continental crust) assume it has either the same composition as common chondrites or can be inferred from terrestrial samples that are supplemented with chondritic trends for refractory lithophile elements. It has been argued that relative to such BSE estimates, the MORB source region is significantly depleted in incompatible trace elements (including the heat-producing elements U, Th and K) (e.g. McDonough and Sun, 1995; Allègre et al., 2001; Javoy et al., 2010). The corollary to this is the existence of a 'hidden reservoir' (see Allègre et al., 1996; Kellogg et al., 1999; Tackley, 2007, for further discussion). Such a reservoir has been proposed to comprise large parts of the lower-mantle (e.g. Allègre et al., 1996; Kellogg et al., 1999) or may reside inside LLSVPs (e.g. Sramek et al., 2013).

However, the recent observation that the ${ }^{142} \mathrm{Nd} /{ }^{144} \mathrm{Nd}$ ratio is higher on Earth than in chondritic meteorites (Boyet and Carlson, 2005, 2006) has led to the alternative proposition that the BSE is non-chondritic (e.g. Caro and Bourdon, 2010; Campbell and O'Neill, 2012), in which case a hidden reservoir may be unnecessary. Other studies have argued that terrestrial sample estimates of the MORB source composition are

biased towards a depleted end-member (e.g. Lyubetskaya and Korenaga, 2007; Davies, 2009). Their revised estimates suggest that the MORB source contains up to $100 \%$ more incompatibles than was previously assumed, implying that, at most, a small amount of distinct material needs to remain sequestered from the convecting mantle (e.g. Lyubetskaya and Korenaga, 2007; Davies, 2009).

Hence, although geochemical constraints clearly require a heterogenous mantle, the temporally and spatially integrated signal provided by isotopic and trace-element trends are unable to constrain the distribution and scale of such heterogeneity.

\subsection{Current dynamical views on the nature of compositional heterogeneity}

The geochemical data indicate that three compositions could contribute to chemically distinct LLSVPs: (i) recycled oceanic lithosphere; (ii) primitive BSE mantle, unaffected by continental crust extraction; and (iii) a reservoir comprising cumulates from an early differentiation event.

To form long-lived 'piles', material must be substantially denser than the surrounding MORB-source (pyrolitic) mantle. A number of dynamic modelling studies have investigated the conditions necessary to preserve dense material at the base of the mantle throughout Earth's history (e.g. Tackley, 1998; Davaille, 1999; McNamara and Zhong, 2004; Deschamps and Tackley, 2008, 2009; Tan et al., 2011; Bower et al., 2013). This needs to be achieved without fully layering the mantle, which is precluded by a number of geophysical observations (see Davies, 1999, 2011, for detailed discussion). It was found that for densities 2-3\% higher 
(a)

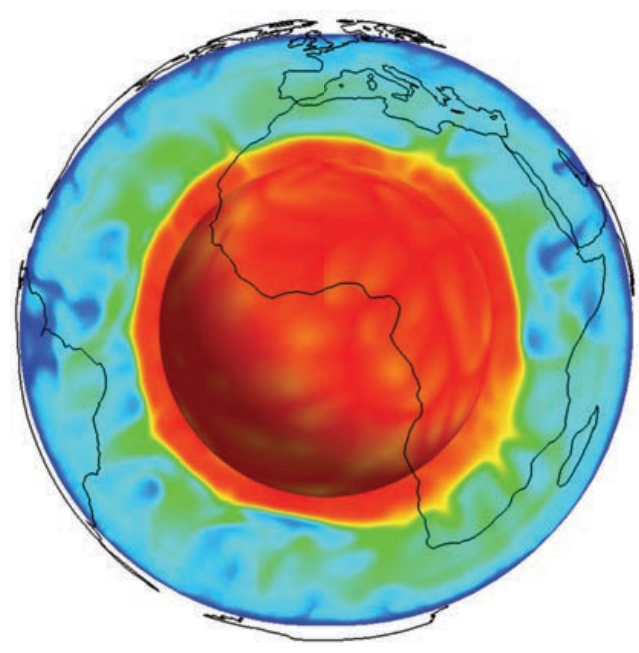

(b)

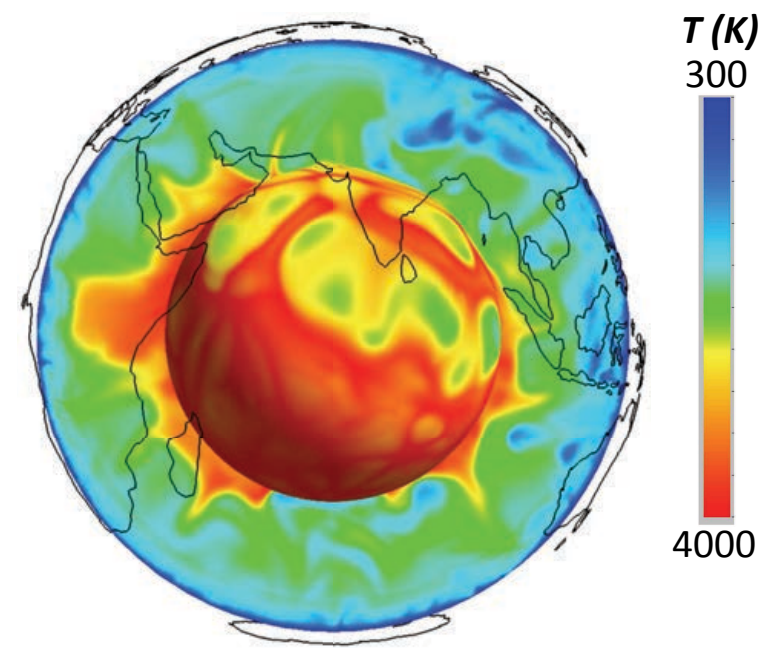

Figure 2: Two conceptual models of mantle structure, from Styles et al. (2011) and Davies et al. (2012): (a) a layered case, where chemically distinct material has a density contrast of $5 \%$ (Buoyancy Number, $B \approx 0.5$ ) when compared to background mantle. Such a large density contrast exceeds the upper bound expected for MORB or Fe-rich compositions relative to a pyrolite and, under such a scenario, dense material forms a hot, stable layer, which covers the entire CMB; (b) a thermo-chemical pile case, where chemically distinct material has a density contrast of $2.5 \%$ relative to background mantle (Buoyancy Number, $B \approx 0.25)$. Such a density contrast is within current estimates for the excess density of MORB and Fe-rich primitive material in comparison to pyrolite at lower-mantle depths, and leads to a discontinuous chemical interface above the CMB, consisting of two piles beneath Africa and the Pacific. These piles are shaped by subducting slabs. Images include a radial surface at 2800 $\mathrm{km}$ depth, a cross section which provides some insight into the distribution of temperature and chemically distinct material as a function of depth, whilst continental boundaries provide geographic reference (reproduced from Styles et al. (2011): Copyright Wiley - Reprinted with permission).

than pyrolite, together with plausible estimates for mantle viscosity and compressibility, piles may sequester material for up to a few Ga, although they are mobile and deform through time (e.g. Zhang et al., 2010; Tan et al., 2011). Such mobile thermo-chemical piles lead to spatial and temporal variations in the CMB heat-flux, which has been proposed to explain the observed variability in geomagnetic field polarity reversal intervals (Zhang and Zhong, 2011; Olson et al., 2013). Material with an excess density of greater than $\sim 3 \%$ tends to form a dense layer that covers the entire CMB, rather than discontinuous piles. Illustrative examples of the temperature field for both layered and discontinuous pile thermo-chemical models are shown in Fig. 2. A similar thermo-chemical pile model is examined herein.

Mantle convection models that recycle plates form piles comprising dense basaltic material (e.g. Christensen and Hofmann, 1994; Xie and Tackley, 2004; Huang and Davies, 2007a,b; Brandenburg et al., 2008). When the isotopic evolution of recycled material is tracked in these models, several observed geochemical trends (such as $\mathrm{Sr}, \mathrm{Nd}, \mathrm{Pb}$ and He isotope ratios) can be reproduced. Most noteworthy is that for densities within the range estimated for MORB under deep mantle conditions: (i) deep mantle piles constitute a relatively small volume fraction of the mantle (a few percent); (ii) much of the heterogeneity that contributes to the geochemical signatures is widely-distributed throughout the mantle; (iii) material with the longest 
residence time does not necessarily occur at the mantle's base (e.g. Brandenburg and van Keken, 2007; Brandenburg et al., 2008); and (iv) piles do not govern the convective planform, but are shaped by the action of downwellings (i.e. they change shape and location over the time-scale of a Wilson cycle). Furthermore, billion-year residence times, which allow isotopic ratios to evolve to the range observed in a number of OIBs (Hofmann, 2003), can be achieved even if the recycled material has no excess density when compared to surrounding mantle (e.g. Huang and Davies, 2007a).

Although much of the observed geochemical heterogeneity can be explained by recycled oceanic crustal material, an additional ancient mantle component is required (e.g. Jackson and Carlson, 2011). This longlived heterogeneity can remain shielded from melting either by a high intrinsic density and sequestration in the deep mantle or by a high melting temperature. Hence, both geochemical and geodynamic constraints neither require nor rule out that LLSVPs contain significant compositional heterogeneity. This, therefore, leaves the question of whether geophysical observations can distinguish between LLSVPs representing: (i) thermally dominated plume clusters, where chemical heterogeneity plays a negligible role in governing the underlying dynamics; (ii) chemical piles, in which substantial fractions of oceanic crust reside for hundreds of Myr; or (iii) chemical piles, which represent a reservoir of dense primitive material. Characteristics that may be geophysically observable include major-element signatures that significantly modify density and/or seismic velocity (e.g. Labrosse et al., 2007; Nakagawa et al., 2010; Mosca et al., 2012), or sequestered heat-producing elements if concentrated in large-scale piles (e.g. Sramek et al., 2013).

\subsection{Seismic evidence for thermo-chemical LLSVPs}

Seismology provides the most direct and detailed observations of Earth's internal structure and, hence, the debate on the nature of LLSVPs has been centred on seismological arguments, which include the correlation of seismic structure with large igneous provinces and hotspots, commonly assumed to represent the surface expression of mantle plume heads and tails, respectively (e.g. Campbell and Griffiths, 1992). The principal arguments invoked in favour of compositionally distinct LLSVPs are the following:

1. LLSVPs have a longer wavelength structure than that predicted by dynamic models in which purely thermal upwellings cluster away from deeply subducted slabs (e.g. Bull et al., 2009).

2. Imaged LLSVP shear-wave velocity anomalies of -2 to $-5 \%$ (e.g. Wang and Wen, 2007; Houser et al., 2008; Ritsema et al., 2011) are considered too large for purely thermal structures (e.g. Karato and Karki, 2001; Brodholt et al., 2007).

3. Shear-wave velocity gradients ranging from $1.3-6 \% / 100 \mathrm{~km}$ have been identified along the margins 
(and occasionally within the interior) of both the African and Pacific LLSVPs (Ritsema et al., 1998; Ni et al., 2002; Wang and Wen, 2004; To et al., 2005), indicating that these features, at least locally, have sharp sides. It is expected that purely thermal structures would be smoothed by diffusive heat loss and, hence, would be unable to explain such rapid velocity variations (e.g. Ni et al., 2002).

4. Hernlund and Houser (2008) find that the distribution of deep mantle shear-wave velocity anomalies exhibits a slow tail in several global tomographic models, whilst compressional-wave velocity anomalies form single-peaked Gaussian distributions. They attribute this tail to a combination of the postperovskite phase transition (below $\sim 2400 \mathrm{~km}$ depth) and chemical heterogeneity (at shallower depths).

5. LLSVPs have a different expression in shear and compressional wavespeed anomalies, reflected in high $R=\partial \ln V_{S} / \partial \ln V_{P}$ ratios in the deep mantle (e.g. Robertson and Woodhouse, 1995; Ritsema and van Heijst, 2002). Such elevated ratios are considered incompatible with a purely thermal origin (e.g. Karato and Karki, 2001; Saltzer et al., 2001).

6. Shear-wave and bulk-sound velocity anomalies have been found to be anti-correlated within (and outside) LLSVPs and possibly over large depth ranges of the lower-mantle (e.g. Su and Dziewonski, 1997; Kennett et al., 1998; Masters et al., 2000). As shear and bulk moduli respond to temperature in the same direction, this appears inconsistent with purely thermal structures.

7. Similarly, predicted anti-correlations between shear-wave velocity and density anomalies inside (and outside) LLSVPs would preclude a thermal origin (e.g. Ishii and Tromp, 1999; Trampert et al., 2004).

8. 1-D seismic reference models (e.g. Dziewonski and Anderson, 1981; Kennett et al., 1995) cannot be reconciled with seismic velocities predicted for an isochemical and thermally well-mixed mantle and may require a superadiabatic temperature gradient or a variation in composition with depth (e.g. da Silva et al., 2000; Deschamps and Trampert, 2004; Cammarano et al., 2005; Matas et al., 2007; Khan et al., 2008; Cobden et al., 2009).

9. Finally, several studies infer that hotspots and the reconstructed eruption sites of LIPs concentrate above LLSVP margins (e.g. Thorne et al., 2004; Torsvik et al., 2006; Burke et al., 2008; Torsvik et al., 2010) (Fig. 3). This correlation has been explained by the preferential triggering of plumes at the interface between background mantle and high density, and possibly also high bulk-modulus, piles (e.g. Tan et al., 2011; Steinberger and Torsvik, 2012). Such correlations have further led to the proposal that LLSVPs have remained stable in location and shape over at least 200-250 Myr and, potentially, through several Wilson cycles (Burke et al., 2008), possibly stabilised by Earth's rotation, such that 


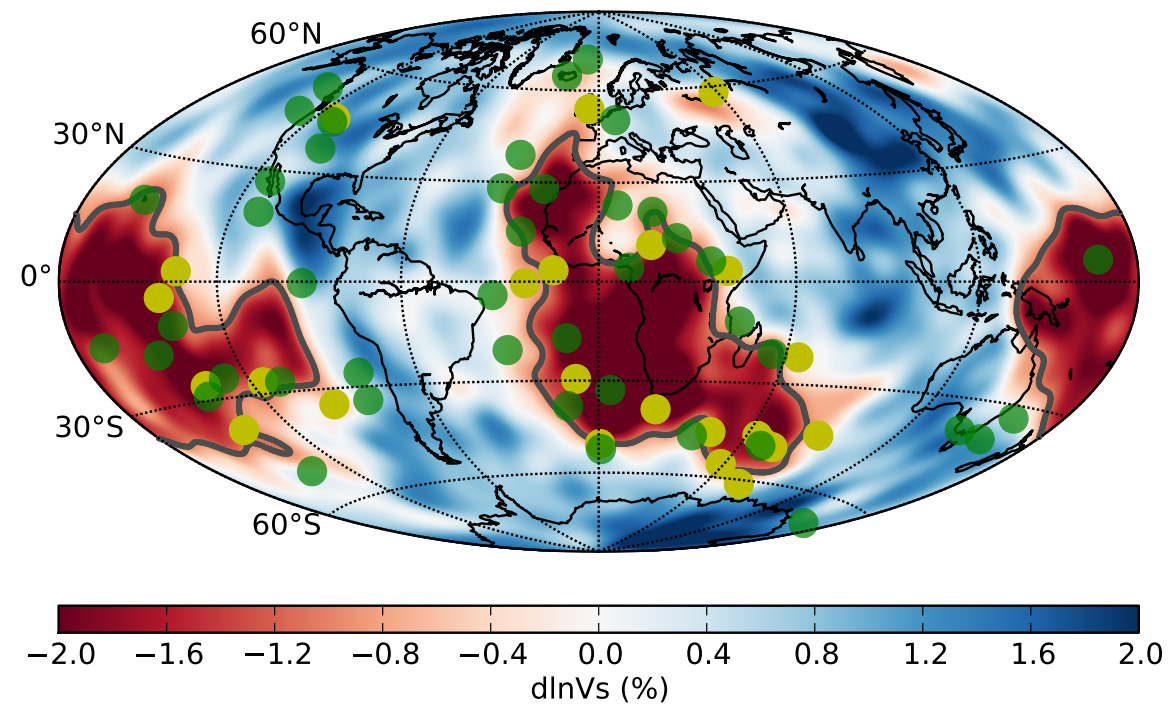

Figure 3: Surface hotspot locations (Green circles: Steinberger, 2000) and the reconstructed eruption sites of large igneous provinces (Yellow circles: Torsvik et al., 2006, 2008b), plotted above the shear-wave tomography model SMEAN (Becker and Boschi, 2002), at $2800 \mathrm{~km}$ depth. The $-1.0 \% \mathrm{~d} \ln V_{S}$ contour is shown in grey.

they impose a bottom-up control on surface tectonics (Dziewonski et al., 2010). Such temporal and spatial LLSVP stability would require a significant contribution from excess chemical density.

\section{Comparing synthetic and observed seismic structure}

\subsection{Methods}

To test to what extent the seismic characteristics summarised in Section 2.3 require that LLSVPs constitute thermo-chemical piles and, if so, whether they can constrain pile composition, over recent years we have examined a set of global mantle convection models, in which the distribution of heterogeneity is dictated by 300 Myr of assimilated plate motion histories. We have examined a suite of simulations, with a focus on two end-member cases: (i) a purely thermal scenario, with no chemical heterogeneity; and (ii) a thermo-chemical pile scenario, where chemically dense material focuses into distinct discontinuous structures at the mantle's base, beneath Africa and the Pacific.

\subsubsection{Dynamic convection models}

Global temperature $(T)$, pressure $(P)$ and compositional $(X)$ fields are generated using a modified and benchmarked version of the compressible spherical mantle convection code TERRA (e.g. Baumgardner, 1985; Bunge et al., 1997; Davies and Davies, 2009; Davies et al., 2013). Models incorporate compressibility, in the form of the anelastic liquid approximation, with radial reference values represented through a Murnaghan equation of state. They achieve an internally heated Rayleigh number of $\operatorname{Ra}_{H} \approx 5 \times 10^{8}$ and a volume 


\begin{tabular}{llll}
\hline \hline Paramater & Symbol & Value & Units \\
\hline Surface temperature & $\mathrm{T}_{s}$ & 300 & $\mathrm{~K}$ \\
CMB temperature & $\mathrm{T}_{\mathrm{cmb}}$ & 4000 & $\mathrm{~K}$ \\
Internal heating rate & $\mathrm{H}$ & $5.5 \times 10^{-12}$ & $\mathrm{~W} \mathrm{~kg}^{-1}$ \\
Reference viscosity & $\mu_{0}$ & $3.0 \times 10^{21}$ & $\mathrm{~Pa} \mathrm{~s}$ \\
Lithospheric multiplication-factor & $\Delta \mu_{L i}$ & 100 & - \\
$410 \mathrm{~km}$ multiplication-factor & $\Delta \mu_{410}$ & 5 & - \\
660 km multiplication-factor & $\Delta \mu_{660}$ & 30 & - \\
Viscosity: depth dependence & $\mathrm{V}_{a}$ & 2.99 & - \\
Viscosity: temperature dependence & $\mathrm{E}_{a}$ & 4.61 & - \\
Clapeyron slope: 410 km & $\mathrm{Cl}_{410}$ & $1.5 \times 10^{6}$ & $\mathrm{M} \mathrm{Pa} \mathrm{K}$ \\
Clapeyron slope: 660 km & $\mathrm{Cl}_{660}$ & $-1.0 \times 10^{6}$ & $\mathrm{M} \mathrm{Pa} \mathrm{K}^{-1}$ \\
Surface density & $\rho_{s}$ & 3500 & $\mathrm{~kg} \mathrm{~m}^{-3}$ \\
CMB density & $\rho_{\mathrm{cmb}}$ & 5568 & $\mathrm{~kg} \mathrm{~m}^{-3}$ \\
Surface thermal expansivity & $\alpha_{s}$ & $3.8 \times 10^{-5}$ & $\mathrm{~K}^{-1}$ \\
CMB thermal expansivity & $\alpha_{\mathrm{cmb}}$ & $1.2 \times 10^{-5}$ & $\mathrm{~K}-1$ \\
Superadiabatic temperature contrast & $\Delta T_{s}$ & 2650 & $\mathrm{~K}$ \\
Total temperature contrast & $\Delta T$ & 3700 & $\mathrm{~K}$ \\
Adiabatic footing temperature & $\mathrm{T}_{\mathrm{pot}}$ & 1600 & $\mathrm{~K}$ \\
Surface thermal conductivity & $k_{\mathrm{S}}$ & 4.0 & $\mathrm{~W} \mathrm{~m} \mathrm{~K}^{-1} \mathrm{~K}^{-1}$ \\
CMB thermal conductivity & $k_{\mathrm{cmb}}$ & 6.0 & $\mathrm{~W} \mathrm{~m} \mathrm{~K}^{-1}$ \\
Specific heat capacity & $C_{p}$ & 1134 & $\mathrm{~J} \mathrm{~kg} \mathrm{~K}^{-1}$ \\
Surface Dissipation number & $D i_{s}$ & $\approx 1.0$ & - \\
Volumetric Dissipation number & $D i_{V}$ & $\approx 0.5$ & - \\
Internally heated Rayleigh number & $R a_{H}$ & $\approx 5.0 \times 10^{8}$ & - \\
Basally heated Rayleigh number & $R a_{b}$ & $\approx 3.0 \times 10^{7}$ & - \\
\hline \hline & & & \\
\hline
\end{tabular}

Table 1: Parameters common to all models. Rayleigh numbers are calculated based upon surface reference values.

averaged Dissipation number of 0.5, which are similar to estimates for Earth's mantle. Surface velocities are assimilated via 300 Myr of plate motion reconstructions (Stampfli and Borel, 2002; Stampfli and Hochard, 2009), at discrete 1 Myr intervals, with a free-slip boundary condition specified at the CMB. Note that surface velocities are assimilated at a vigour consistent with the underlying simulation (i.e. surface RMS velocities of the free-slip stage of our simulation are consistent with those of assimilated model), to avoid excessive viscous dissipation beneath plates. Isothermal boundary conditions are prescribed at the surface $(300 \mathrm{~K})$ and CMB $(4000 \mathrm{~K})$, with the mantle also heated internally, at roughly chondritic rates $\left(5.5 \times 10^{-12}\right.$ $\mathrm{W} \mathrm{kg}^{-1}$ ). Phase changes are incorporated at 410 and $660 \mathrm{~km}$ depth, whilst thermal conductivity increases linearly with depth, from a value of $4 \mathrm{~W} \mathrm{~m}^{-1} \mathrm{~K}^{-1}$ at the surface to $6 \mathrm{~W} \mathrm{~m}^{-1} \mathrm{~K}^{-1}$ at the CMB (e.g. de Koker, 2010). Viscosity varies as a function of depth (z) and temperature (T), following the relation:

$$
\mu(z, T)=\left\{\begin{array}{cc}
\mu_{0} \Delta \mu_{L i} \exp \left[V_{a} z^{\prime}-E_{a} T^{\prime}\right] & z<100 \mathrm{~km} \\
\mu_{0} \exp \left[V_{a} z^{\prime}-E_{a} T^{\prime}\right] & 100 \mathrm{~km} \leq z<410 \mathrm{~km} \\
\mu_{0} \Delta \mu_{410} \exp \left[V_{a} z^{\prime}-E_{a} T^{\prime}\right] & 410 \mathrm{~km} \leq z<660 \mathrm{~km} \\
\mu_{0} \Delta \mu_{660} \exp \left[V_{a} z^{\prime}-E_{a} T^{\prime}\right] & z \geq 660 \mathrm{~km}
\end{array}\right.
$$


(a) Viscosity

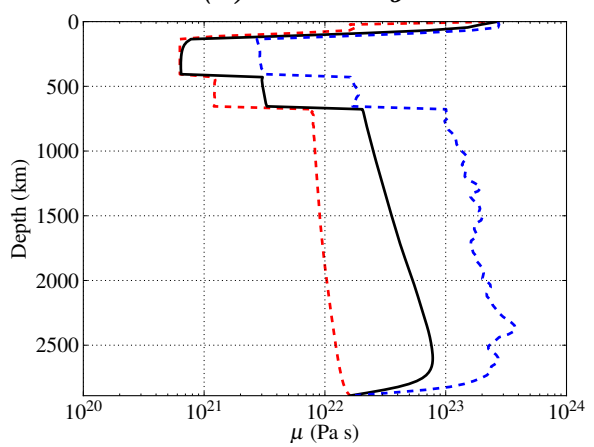

(b) Thermal expansivity

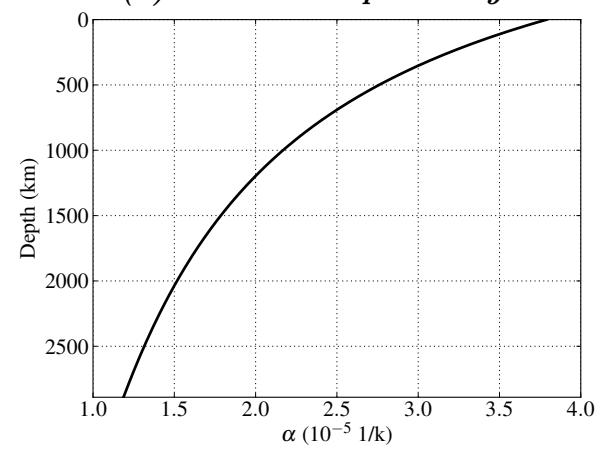

(c) Reference density

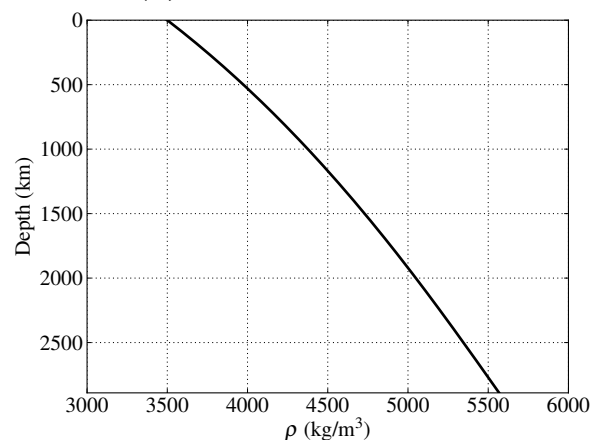

Figure 4: (a) Radial viscosity profile for the isochemical model examined herein (the thermo-chemical pile model has a similar structure, with minor differences in the lowermost mantle). Note that red, black and blue lines denote the minimum, mean and maximum viscosities, respectively (at any given depth). The minimum viscosity is limited to $7 \times 10^{20} \mathrm{~Pa}$ s, to ensure numerical stability; (b) Thermal expansivity and (c) reference density profiles, for the models examined herein.

where $T^{\prime}$ and $z^{\prime}$ are non-dimensionalised by $\Delta T$ and mantle depth, respectively, whilst $V_{a}$ and $E_{a}$ are nondimensional constants controlling the sensitivity of viscosity to depth and temperature. Our choice of $V_{a}$ and $E_{a}$ yields an Earth-like viscosity-depth profile, which results in model slab sinking rates that are consistent with those inferred from tomographic images.

For initial conditions, a standard convection model (with free-slip surface) is run until a thermal quasisteady-state is achieved $(\approx 1 \mathrm{Gyr})$. Early Carboniferous mantle heterogeneity is then approximated by running models with global plate configurations fixed to the reconstruction at $300 \mathrm{Ma}$, for $\approx 50 \mathrm{Myr}$, before allowing models to evolve towards the present-day. The chemical field $(X)$ is simulated via the ratio tracer particle method (Tackley and King, 2003; Stegman et al., 2003), with $\approx 2.0 \times 10^{9}$ active tracers, of two distinct types (dense material, $X=1$; regular material, $X=0$ ). Key model parameters are provided in Table 1, with radial profiles of density, thermal expansivity and viscosity in Fig. 4.

We test two end-member scenarios: a purely thermal (isochemical) model and a thermo-chemical model with dense piles of chemical heterogeneity, which, in total, comprise $3 \%$ of the mantle's volume. The thermochemical model is initiated with a $175 \mathrm{~km}$ thick basal layer of excess density $2.75 \%$ (buoyancy number, $B=\Delta \rho_{X} / \Delta \rho_{T} \approx 0.275$, where $\Delta \rho_{T}=\alpha_{s} \rho_{s} \Delta T_{s}$ ), which progressively deforms as the model evolves. Apart from the inclusion of dense material in the thermo-chemical model, both cases are identical. However, as we will show, their convective planforms and seismic expressions differ substantially, which allows for meaningful comparisons between each case and seismic observations of Earth's present day mantle. It should also be noted that chemical piles influence the CMB heat flux, with the present-day CMB heat flux decreasing from $\sim 12 \mathrm{TW}$ in the purely thermal case, to around $\sim 9 \mathrm{TW}$ in the thermo-chemical case.

Our models have many Earth-like characteristics, in terms of convective vigour, thermal structure, surface heat flux and the geographic pattern of heterogeneity (controlled by the assimilated plate motion history). 
However, a few limitations should be noted:

i. The parameters of our simulations are not fully self-consistent with the thermodynamic database utilised in converting from physical to seismic structure, the key difference being that we exclude dynamic effects of the post-perovskite phase transition, which has been shown to destabilise the thermal boundary layer above the CMB (e.g. Nakagawa and Tackley, 2004; Tosi et al., 2010; Hunt et al., 2012).

ii. The temperature sensitivity of viscosity in our models is lower than that on Earth (e.g. Ranalli, 1995; Karato, 2008), with no dependence on composition or stress. As a result, our downgoing slabs lack the strength of slabs on Earth and are likely too thick, which may alter their passage through the mantle. This manifests itself mostly within the transition zone, where, despite the inclusion of an endothermic phase transition and viscosity jump, modelled slabs stall less than is indicated by tomographic images (e.g. Li et al., 2008; Fukao and Obayashi, 2013) or is predicted by recent complex rheology numerical studies (e.g. Garel et al., 2014). However, we have verified that our viscosity profile results in lowermantle slabs being located at depths that are consistent with tomographic images.

iii. In our thermo-chemical cases, piles form from an initial layer of dense material and are shaped by subduction history. Accordingly, their shape and seismic expression may differ to those formed via the recycling of oceanic plates (e.g. Brandenburg et al., 2008; Nakagawa et al., 2010), although such recycling models also create two dense piles, even without assimilating plate motion histories. We show only comparisons between a single thermo-chemical pile model and a purely thermal model, from a suite of cases that have previously been examined, where the volume-fraction and excess density of chemical material is varied. Thermo-chemical models with increased volume-fractions of dense material (of similar density contrast) produce piles that cover a larger portion of the CMB and extend further into the mid-mantle, resulting in stronger deep mantle seismic anomalies and a radial distribution of heterogeneity that decreases the correlation between thermo-chemical model predictions and imaged structure (Davies et al., 2012). Models with decreased volume-fractions of dense material, or a lower chemical density contrast, do not generate coherent thermo-chemical piles within the 300 Myr of plate motion histories available.

iv. Present-day synthetic LLSVP shape is sensitive to the imposed initial conditions and the plate model (and its associated reference frame) utilised as a kinematic surface velocity boundary condition (e.g. Shephard et al., 2012). Several studies have demonstrated that the most recent 120-250 Myr of plate motion histories can focus plume clusters and compositional piles into two distinct deep mantle structures beneath Africa and the Pacific (e.g. Bunge et al., 2002; McNamara and Zhong, 2005; Bull et al., 2009; 


\begin{tabular}{cccc}
\hline \hline Component & Pyrolite & Basaltic & Fe-Rich \\
\hline $\mathrm{SiO}_{2}$ & 38.71 & 51.57 & 40.03 \\
$\mathrm{MgO}$ & 49.85 & 14.94 & 43.37 \\
$\mathrm{FeO}$ & 6.17 & 7.06 & 11.68 \\
$\mathrm{CaO}$ & 2.94 & 13.88 & 3.24 \\
$\mathrm{Al}_{2} \mathrm{O}_{3}$ & 2.22 & 10.19 & 1.68 \\
$\mathrm{Na}_{2} \mathrm{O}$ & 0.11 & 2.18 & 0.0 \\
\hline \hline
\end{tabular}

Table 2: Major-oxide compositions (in mol \%) examined herein.

Schuberth et al., 2009b; Steinberger and Torsvik, 2012; Bower et al., 2013). The exact shape and extent of these provinces, however, may depend on subduction histories beyond $300 \mathrm{Ma}$ (e.g. Zhang et al., 2010). We note that plate motion histories prior to $150 \mathrm{Ma}$ are relatively poorly constrained in the Pacific but reasonably well constrained by the continental record in the Atlantic/Eurasian domains (e.g. Torsvik et al., 2008a; Stampfli and Hochard, 2009; Zhang et al., 2010).

\subsubsection{Conversion to seismic structure}

Predicted physical structures are converted into density and elastic parameters using a thermodynamic approach for the Na-CaFMAS database (e.g. Stixrude and Lithgow-Bertelloni, 2005, 2011). We account for the effects of anelasticity following model Q4 of Goes et al. (2004), which has a relatively low temperature sensitivity. Uncertainties in parameters and the equation of state used in the conversion translate into uncertainties in absolute lower-mantle $\mathrm{V}_{P}$ and $\mathrm{V}_{S}$ of about $\pm 0.2 \mathrm{~km} / \mathrm{s}$ (e.g. Cammarano et al., 2005; Cobden et al., 2009). Anelasticity enhances the temperature sensitivity of seismic velocities (e.g. Karato, 1993; Goes et al., 2004) and, although its importance in the lower-mantle is less than the upper mantle (e.g. Brodholt et al., 2007), it is a systematic effect that should not be neglected (Matas and Bukowinski, 2007), particularly within the mantle's lower thermal boundary layer, where lateral temperature anomalies of 1000$1500 \mathrm{~K}$ are expected (e.g. Lay et al., 2008; Schuberth et al., 2009b; Davies et al., 2012). Uncertainties in the temperature sensitivity of seismic velocities are about $+1 \%,-2 \%$ per $1000 \mathrm{~K}$ in $\partial \ln V_{S} / \partial \mathrm{T}$ and $+0.4 \%,-0.5 \%$ per $1000 \mathrm{~K}$ in $\partial \operatorname{lnV}_{P} / \partial \mathrm{T}$ (Cobden et al., 2009) (Fig. 5).

We consider three synthetic seismic cases: a purely thermal case with a pyrolitic composition and two compositional cases, both inferred from the same dynamic thermo-chemical model, but assuming that the dense material is either recycled and has a basaltic composition, or is primitive and has an Fe-rich chondritic composition (Table 2). At lowermost mantle depths, the basaltic and Fe-rich compositions have similar excess densities, which justifies the use of the same dynamic model. However, they have different seismic signatures, with basalt somewhat faster in $\mathrm{V}_{P}$ and significantly faster in $\mathrm{V}_{S}$ relative to pyrolite, whilst the Fe-rich composition is slow in both $\mathrm{V}_{P}$ and $\mathrm{V}_{S}$. Many other compositions, including peridotites, harzburgites 


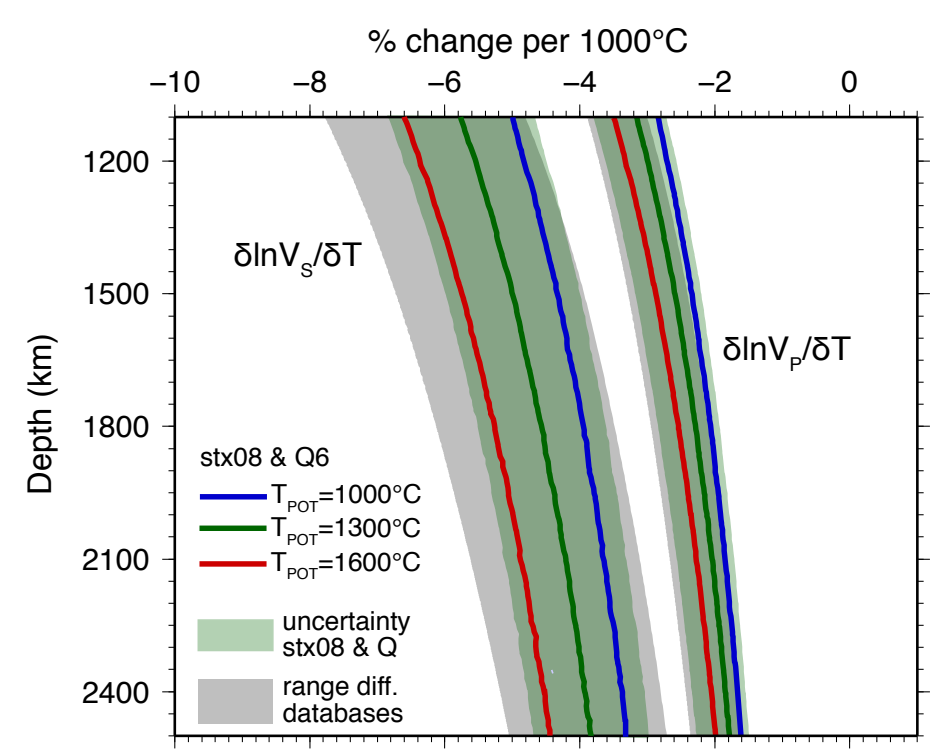

Figure 5: Shear and compressional velocity sensitivity to temperature (after Cobden et al., 2009). The reference profiles use the stx08 thermodynamic database (Xu et al., 2008) and anelasticity model Q6 (Goes et al., 2004). The uncertainty in $\mathrm{dV} / \mathrm{dT}$ at any given reference potential temperature $\left(\mathrm{T}_{\text {pot }}\right.$ ) is dominated by uncertainties (from Xu et al., 2008) in elastic parameters (compare uncertainties in derivatives along a $1300^{\circ} \mathrm{C}$ adiabat for single database, in light green, and differences between databases (Cobden et al., 2009), in grey, with the difference between $1000^{\circ} \mathrm{C}$-adiabat derivatives, where anelastic effects are minimal, and $1300^{\circ} \mathrm{C}$ derivatives, where anelasticity does contribute). However, anelasticity leads to systematic shifts in $\mathrm{dV} / \mathrm{dT}$ with increased sensitivity at high $\mathrm{T}$ (red curve) and decreased sensitivity at low $\mathrm{T}$ (blue curve). Neglecting anelasticity leads to systematic underestimation of the temperature sensitivity of seismic velocities, in particular $\mathrm{V}_{S}$. Note that the seismic conversions undertaken herein utilised the stx11 database, which has a similar elastic sensitivity to stx08, and anelasticity model Q4, which has a lower temperature sensitivity than Q6.

and various chondrites have velocities that are similar to a pyrolite (Cobden et al., 2009). The only other compositional change that produces a distinct seismic expression is significant silica enrichment, as might be expected in a cumulate formed from a magma ocean (e.g. Walter et al., 2004). Although high silica content results in faster $\mathrm{V}_{P}$ and slightly faster $\mathrm{V}_{S}$ than a pyrolite, it does not increase density (e.g. Cobden et al., 2009), which is a requirement to form stable piles. An example of compressional, shear and bulk-sound velocity structures for a purely thermal model is shown in Fig. 6. At $2800 \mathrm{~km}$ depth, where the radial surface is shown, anti-correlated bulk-sound and shear-wave velocity anomalies occur due to the presence of post-perovskite (e.g. Wookey et al., 2005; Ammann et al., 2010; Stixrude and Lithgow-Bertelloni, 2011).

\subsubsection{Tomographic resolution filtering}

Our synthetic seismic structures cannot be directly compared with tomographic models, as tomographic structures are strongly affected by resolution, due to the uneven source-receiver distribution and the type of data used, in addition to model parameterisation and regularisation. Thus, comparison with seismic constraints requires either propagation of seismic waves through the synthetic structures and direct comparison with data, or conducting a seismic resolution test with the proposed synthetic structure as input. 


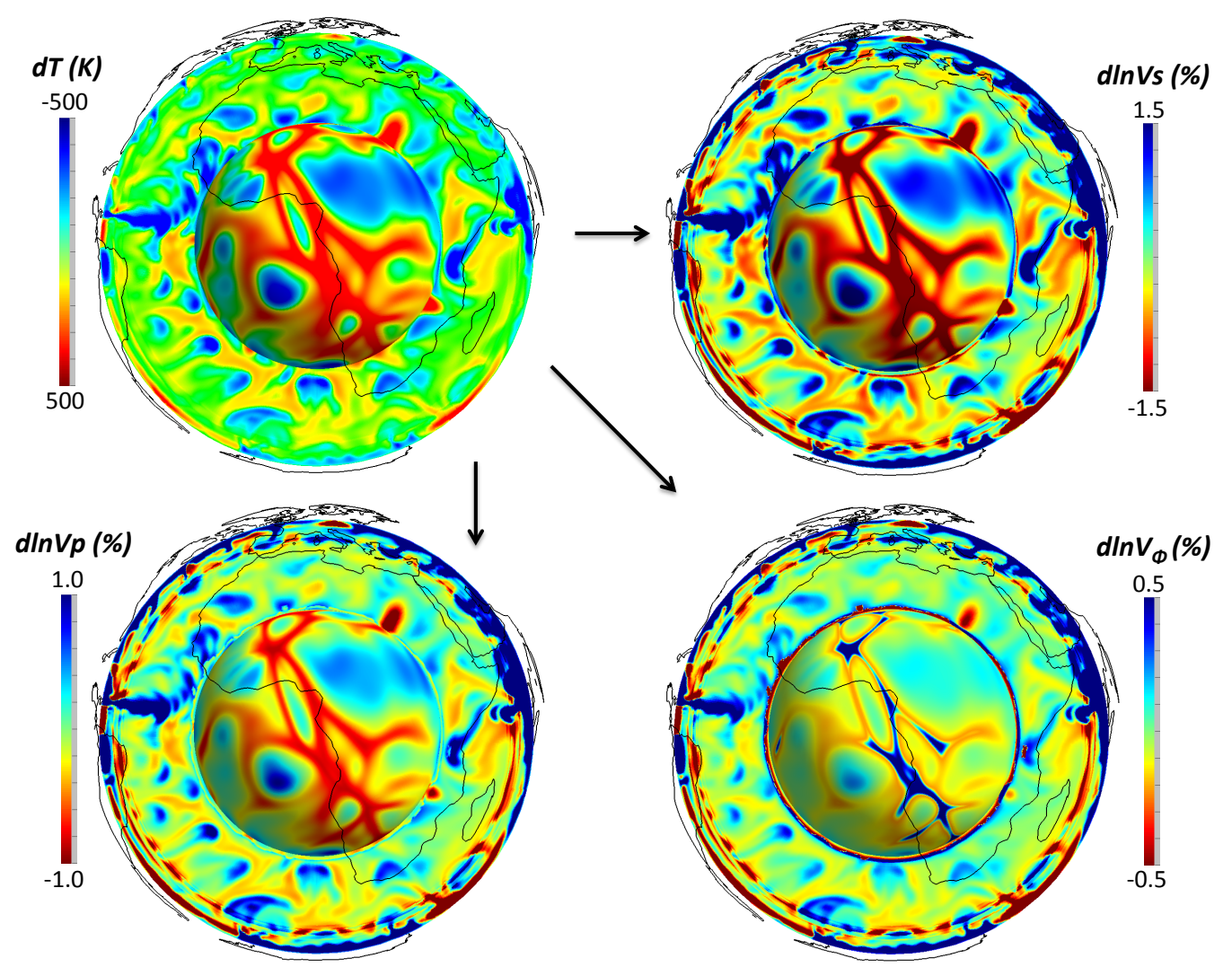

Figure 6: An illustration of our seismic conversion, for an example isochemical model of pyrolitic mantle composition, in an Africa-centred view. Each image includes a radial surface at $2800 \mathrm{~km}$ depth and a cross-section, whilst continental boundaries provide geographic reference. Modelled temperature and pressure fields are converted into elastic parameters via a thermodynamic approach (Stixrude and Lithgow-Bertelloni, 2005, 2011), which accounts for the sensitivity of seismic velocities to pressure, temperature, composition and phase, inclusive of the post-perovskite phase at lowermost mantle depths. Elastic velocities are corrected for the effects of temperature- and pressure-dependent anelasticity, using model Q4 of Goes et al. (2004). Anomalies are shown relative to the model's spherical average profile. Note that no resolution filtering has been applied to the model illustrated here. Anti-correlated bulk-sound and shear-speed anomalies occur due to the presence of post-perovskite.

For most of the results included here, the resolution operator of the global tomographic model S40RTS is applied to our synthetic shear-wave velocity structures (see Ritsema et al., 2007, 2011, for further details).

The key limitation of this filter is that it does not account for theoretical approximations made in forward wave propagation calculations, but otherwise it captures all imaging effects and, hence, allows for a direct comparison between tomographic and synthetic seismic structures in morphology and amplitude.

\subsection{LLSVP long-wavelength pattern}

In Fig. 7, we show unfiltered and filtered shear-wave velocity distributions beneath the African continent for our thermal and basaltic thermo-chemical models. In both cases, the upper mantle planform is dominated by strong downwellings in regions of present-day plate convergence. In the mid-mantle, cold downwellings are prominent beneath North America and South-East Asia, whilst remnants of older subduction are visible above the CMB. These downwellings modulate the location of hot material such that it becomes concentrated 
(b) Thermal (unfiltered)

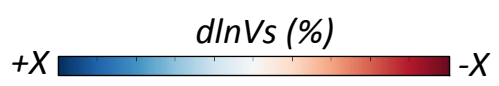

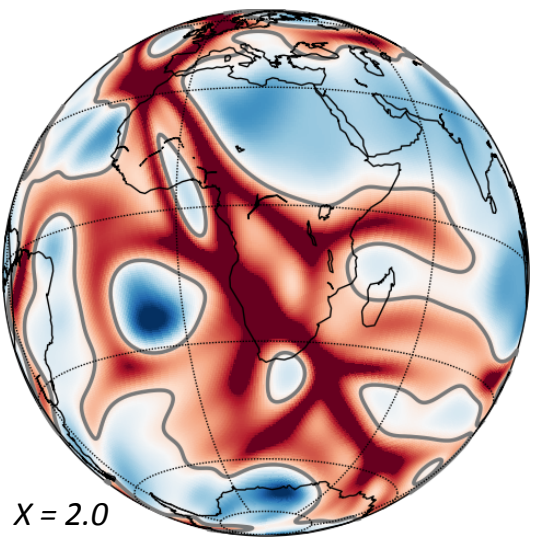

(d) Thermal (filtered)

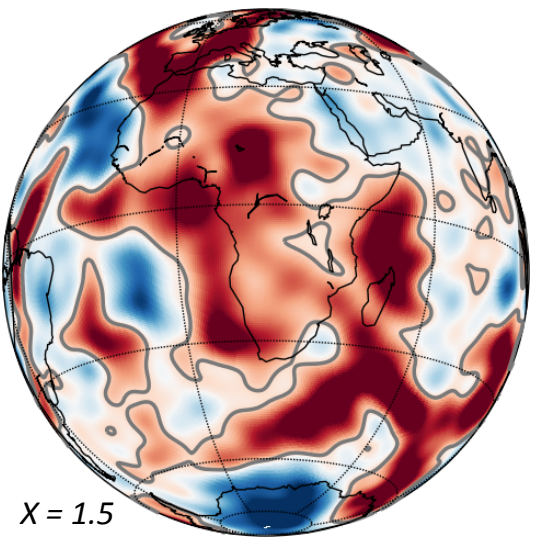

(c) TC 'pile' (unfiltered)

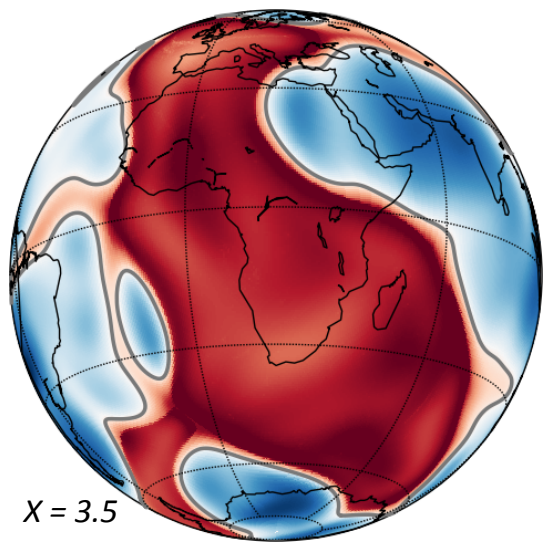

(e) TC 'pile' (filtered)

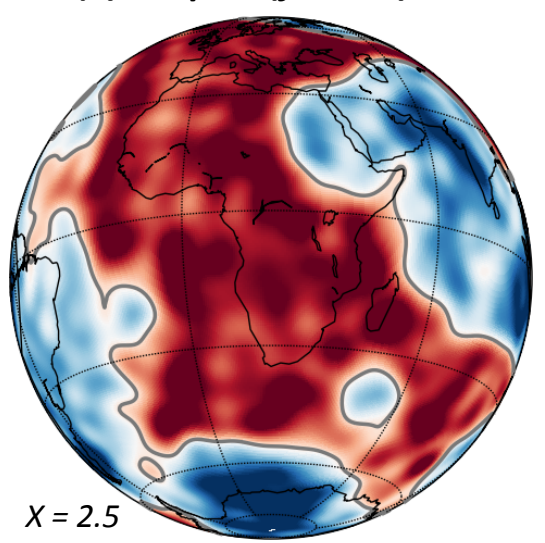

Figure 7: Shear-wave velocity perturbations at $2800 \mathrm{~km}$ depth beneath Africa from: (a) tomographic model S40RTS; (b) our purely-thermal model before and (d) after filtering with the resolution operator of S40RTS; and (c) our thermo-chemical model, before and (e) after filtering. In the isochemical model, $(\mathrm{T}, \mathrm{P}, \mathrm{X})$ is converted into seismic velocity assuming a pyrolitic composition, whilst the thermo-chemical model illustrated here assumes a pyrolitic composition for background mantle and a basaltic composition for the dense chemical component. We account for the geographic bias, smearing and damping inherent to tomographic models using the resolution operator of S40RTS (Ritsema et al., 2007, 2011), thus allowing for direct comparison between our filtered models (d/e) and S40RTS (a). The $-0.3 \%$ grey contour approximates the margin of (a) tomographic and (b-e) synthetic LLSVPs. Continental boundaries provide geographic reference. Note the difference in scale between panels.

beneath Africa and the Pacific. The Pacific anomaly is reasonably circular, whilst the African anomaly, shown in Fig. 7, is a NW-SE trending structure, which to the north curves eastward under Europe and to the south extends into the Indian Ocean. In the purely thermal case, these structures comprise clusters of plumes and interconnected hot linear ridges, whilst they represent discontinuous chemical piles in the thermo-chemical case (Davies et al., 2012).

Our results agree with the predictions of Bull et al. (2009) that unfiltered deep-mantle structure for purely thermal models (Fig. 7b) contains significantly more small-scale heterogeneity than thermo-chemical pile models (Fig. 7c). However, whether this difference in structure can be inferred from relatively smooth global tomographic models depends on the amplitude, position and spacing of heterogeneity, in addition to tomographic parameterisation and resolution. Whilst earlier tomographic models, such as the spherical 
harmonic degree-20 S20RTS model, predicted relatively homogenous LLSVPs, higher resolution global models, such as S40RTS, S20RTS's degree-40 counterpart (Fig. 7a), and regional studies, recover more internal structure (e.g. Wang and Wen, 2007; Houser et al., 2008; He and Wen, 2009; Ritsema et al., 2011).

After application of S20RTS' resolution operator, Bull et al. (2009) concluded that both thermal plumecluster and thermo-chemical pile models shared many characteristics with imaged structure. However, they favoured the thermo-chemical pile scenario as it provided a better qualitative match to S20RTS. When we apply S40RTS' resolution operator to our thermal (Fig. 7d) and thermo-chemical pile (Fig. 7e) models, we find that with the additional structure now imaged in S40RTS it is even more difficult to rule out thermal or thermo-chemical end-members. Focussing solely upon the length-scale and distribution of heterogeneity in Fig. 7(d/e) (i.e. neglecting the increased amplitudes of the thermo-chemical model), both cases show several morphological and geographical characteristics that closely resemble S40RTS.

\subsection{High amplitudes and strong gradients}

It has been argued that a chemical contribution is required to explain the amplitude of low shear-wave velocity anomalies inside LLSVPs (e.g. Karato and Karki, 2001; Brodholt et al., 2007). However, with a CMB temperature of $4000 \pm 200 \mathrm{~K}$, as is inferred from a number of recent geodynamical, seismological and mineral physics studies (e.g. Glatzmaier and Roberts, 1995; Boehler, 2000; Buffett, 2002; Gubbins et al., 2004; Hernlund et al., 2005; Alfè et al., 2007; van der Hilst et al., 2007; Lay et al., 2008), and plausible mantle adiabats (e.g. Brown and Shankland, 1981; Cobden et al., 2009), estimates of the temperature contrast across the mantle's lower thermal boundary layer range from 1000-1500 K (see, for example, Lay et al., 2008). As a result, substantial lateral temperature anomalies, on the order of $1000 \mathrm{~K}$, are expected in hot regions above the CMB. Although imaged velocity anomaly amplitudes are uncertain (e.g. Becker and Boschi, 2002; Ritsema et al., 2007), current estimates of shear-wave velocity sensitivity to temperature (Fig. 5), which consider a wide-range of elastic and anelastic uncertainties (Cobden et al., 2009), imply that such temperature variations can easily account for the -2 to $-5 \%$ amplitudes of shear-wave velocity anomalies inferred for LLSVPs (e.g. Wang and Wen, 2007; Houser et al., 2008; Ritsema et al., 2011). Recent studies, which apply a tomographic resolution filter to synthetic seismic structures from mantle convection models, confirm that sufficient anomaly amplitudes can be generated through thermal heterogeneity alone (e.g. Schuberth et al., 2009a; Davies et al., 2012).

In both thermal and thermo-chemical pile models, the shape of synthetic LLSVPs is modulated by subducting slabs, leading to significant local temperature gradients of 950-1200 K / $100 \mathrm{~km}$ (see Fig. 7b/c), even at depths as shallow as 1500-2000 km (see Davies et al., 2012, for further details). Such thermal 
gradients translate into significant seismic velocity gradients of $3.5-4.5 \% / 100 \mathrm{~km}$, which lie within the seismically inferred range of 1.3-6\%/100 km (e.g. Ni et al., 2002; Wang and Wen, 2004; To et al., 2005). If LLSVPs additionally contain significant Fe-rich (and, hence, low shear-wave velocity) material, seismic velocity gradients are further enhanced, although they are lowered for a basaltic (high shear-wave velocity) composition. Note that lowermost mantle gradients can exceed 10\%/100 km, due to lateral variations in the occurrence of post-perovskite (Stixrude and Lithgow-Bertelloni, 2007; Davies et al., 2012) and are further increased, in all models, if one corrects for anelastic effects using an anelasticity model with a greater temperature sensitivity. These results, therefore, suggest that chemical heterogeneity need not be invoked to explain the high seismic velocity gradients observed in the deep mantle beneath Africa and the Pacific.

\subsection{Skewed distributions of deep mantle shear-wave velocity anomalies}

Hernlund and Houser (2008) analysed lower-mantle seismic heterogeneity distributions for a number of $P$ and $S$-wave tomographic models and demonstrated that they are well-approximated by a single Gaussian distribution at all depths, excluding $\mathrm{V}_{S}$ anomalies below $\sim 2200 \mathrm{~km}$ depth, where a low-velocity tail is observed. This tail increases in both velocity amplitude and abundance towards the CMB. Fig. 8(a) illustrates this tail for S40RTS, which develops a secondary 'bump' from $~ 2600 \mathrm{~km}$ downward. Hernlund and Houser (2008) evaluated differences in resolution between the different tomographic models and, in particular, between $P$ and $S$-wave velocity models, concluding that the slow shear-wave velocity feature is robust, as is the absence of such a tail in compressional-wave velocity models.

We perform a similar analysis of our synthetic shear-wave velocity anomalies, filtered to the resolution of S40RTS, with results presented in Fig. 8(b-d). The distribution of heterogeneity in our purely thermal model (Fig. 8b) develops a low-velocity tail beneath $\sim 2200 \mathrm{~km}$ depth, which increases in both velocity amplitude and abundance towards the CMB, similar to S40RTS, albeit without the slight bump found in the tomographic distributions at depths just above the CMB. Thermo-chemical models (Fig. 8c/d), by contrast, develop a pronounced bimodal lower-mantle heterogeneity distribution, with peaks in heterogeneity observed both at the fast and slow end of the range examined. Such a bimodal distribution is not observed in S40RTS or the other tomographic models analysed by Hernlund and Houser (2008).

Hernlund and Houser (2008) estimate that the anomalously slow shear-wave velocity material comprises a mantle volume fraction of $2 \pm 0.4 \%$. The slow feature imaged in S40RTS is of a somewhat larger volume than the tail predicted in our purely thermal models, but is far weaker than that predicted by our thermochemical models. Our models therefore suggest that if the tail observed in tomographic models is due to the presence of compositional heterogeneity, it must comprise a substantially smaller volume-fraction than 


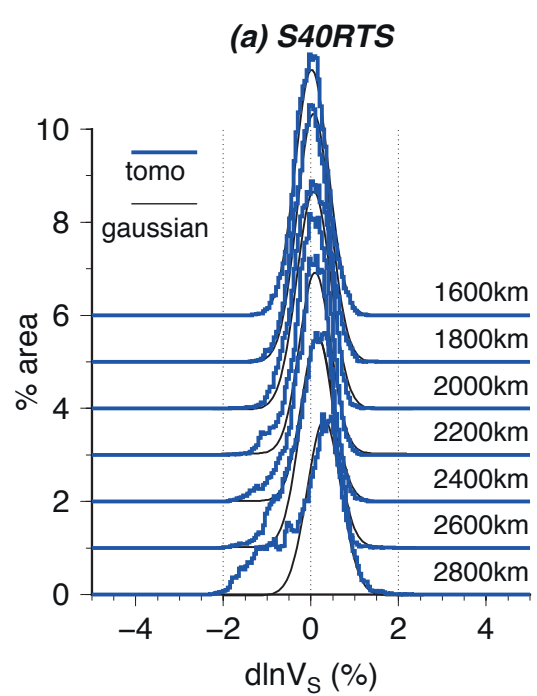

(c) TC basalt

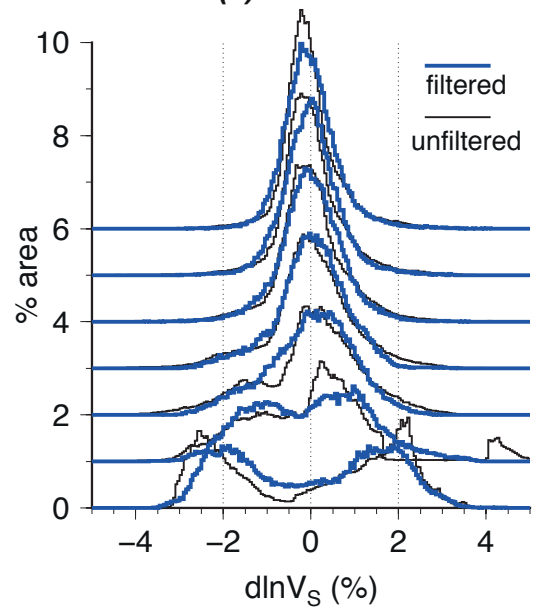

(b) Thermal

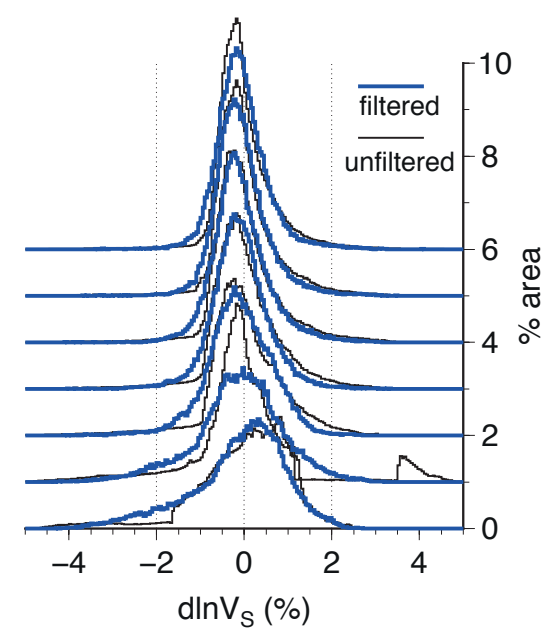

(d) TC Fe-rich

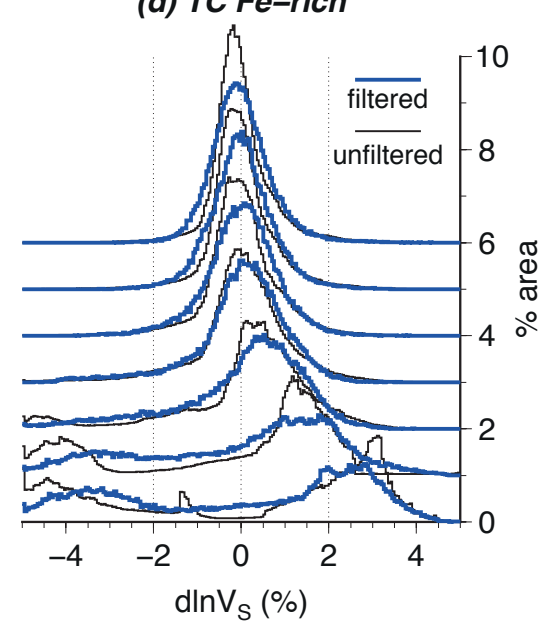

Figure 8: Histograms of shear-wave velocity anomaly distributions, from $1600-2800 \mathrm{~km}$ depth, at $200 \mathrm{~km}$ intervals. Note that plots above $2800 \mathrm{~km}$ depth are each vertically offset by an extra $1 \%$ in areal fraction to allow for comparison. Distributions are for: (a) S40RTS; (b) the purely thermal model; (c) the basaltic thermo-chemical model; and (d) the Fe-rich thermo-chemical model. Blue (black) lines represent S40RTS and each model, after (before) application of S40RTS' resolution operator, whilst black lines in panel (a) are visually-fitted Gaussian curves, which highlight the low-velocity tail below $\sim 2200 \mathrm{~km}$ depth.

the 3\% imposed in our thermo-chemical models. Indeed, given that at least half of the slow tail can be explained without any chemical heterogeneity, if present, dense material inside LLSVPs likely comprises no more than $1 \%$ of the mantle's volume.

Two additional points should be noted from these distributions: (i) model anomalies are calculated relative to the model average. In thermo-chemical models, piles sequester heat in the lowermost mantle, which reduces the layer average velocity in comparison to that of the purely thermal case. Relative to this (slower) average, positive velocity anomalies are enhanced, appearing larger than they do in the purely thermal case at the same depth, despite the fact that the fast material in both cases has similar absolute velocities; (ii) Hernlund and Houser (2008) propose that at least part of the slow tail may be due to the post- 
perovskite phase transition. Our unfiltered distributions demonstrate that the effect of this transition would be a bump with an offset of $\sim 2-4 \%$ between transformed and untransformed material, which is similar to the velocity jump across the transition. This can be seen, for example, in the unfiltered distributions for our thermal and basaltic thermo-chemical models at $2600 \mathrm{~km}$ depth, which show a separate fast bump, relating to the small amount of cold material that has already undergone the transition to post-perovskite. Similarly at $2800 \mathrm{~km}$ depth, untransformed hot perovskite material results in the sharp cut-off of anomalies near $-1.5 \%$ in the thermal and Fe-rich models. Regularisation of the tomographic inversion mostly filters out these small sets of high-amplitude anomalies. The low-velocity tail in the purely thermal model thus principally results from tomographic (under-)resolution of hot, interconnected ridges (Fig. 7b), with strong velocity gradients.

Due to the lack of tomographic $P$ resolution operator, we are unable to undertake a comparable analysis for $\mathrm{V}_{P}$. However, in contrast to the significant velocity increase in $\mathrm{V}_{S}$, the transition to post perovskite leads to a minor decrease in $\mathrm{V}_{P}$ for pyrolitic material. Together with a smaller effect of anelasticity on $\mathrm{V}_{P}$ and overall smaller range of anomalies for the same temperature contrast (see Fig. 5), this results in more symmetric unfiltered thermal model distributions for $P$, and more compact, but nonetheless, bimodal, thermo-chemical distributions.

\subsection{High $\partial \ln \mathrm{V}_{S} / \partial \ln \mathrm{V}_{P}$ and anti-correlated $\partial \ln \mathrm{V}_{S}$ and $\partial \ln \mathrm{V}_{\phi}$}

Elevated lower-mantle ratios of shear and compressional wave-speed anomalies, $R=\partial \ln V_{S} / \partial \ln V_{P}, a r e$ regularly cited as evidence of compositional heterogeneity at depth (e.g. Masters et al., 2000; Karato and Karki, 2001; Saltzer et al., 2001). Fig. 9(a) shows the median value of $R$, as a function of depth, for our three synthetic cases, alongside seismological estimates, which infer $R$ increases from 1.4-2.0 at $1000 \mathrm{~km}$ depth to 2.6-3.4 above the CMB (e.g. Robertson and Woodhouse, 1995; Su and Dziewonski, 1997; Kennett et al., 1998; Masters et al., 2000; Saltzer et al., 2001; Ritsema and van Heijst, 2002). Note that due to the lack of complementary tomographic $P$ and $S$ filters, models and seismic data are not directly comparable in this figure (models have not been filtered to account for limited seismic resolution). Nonetheless, several trends are worth noting.

Above $2200 \mathrm{~km}$ depth, all cases are similar, showing a smooth increase in $R$ with depth, which falls within the bounds of seismic observations. Below this depth, synthetic $R$ varies strongly and differs between each case. Even for the purely thermal case, values within, above and below seismological estimates are predicted, with $R$ increasing to $\sim 5$ at $2750 \mathrm{~km}$ depth. This is due to the post-perovskite phase transition, as relative to perovskite, post-perovskite has an increased shear-wave velocity, a decreased compressional-wave velocity 

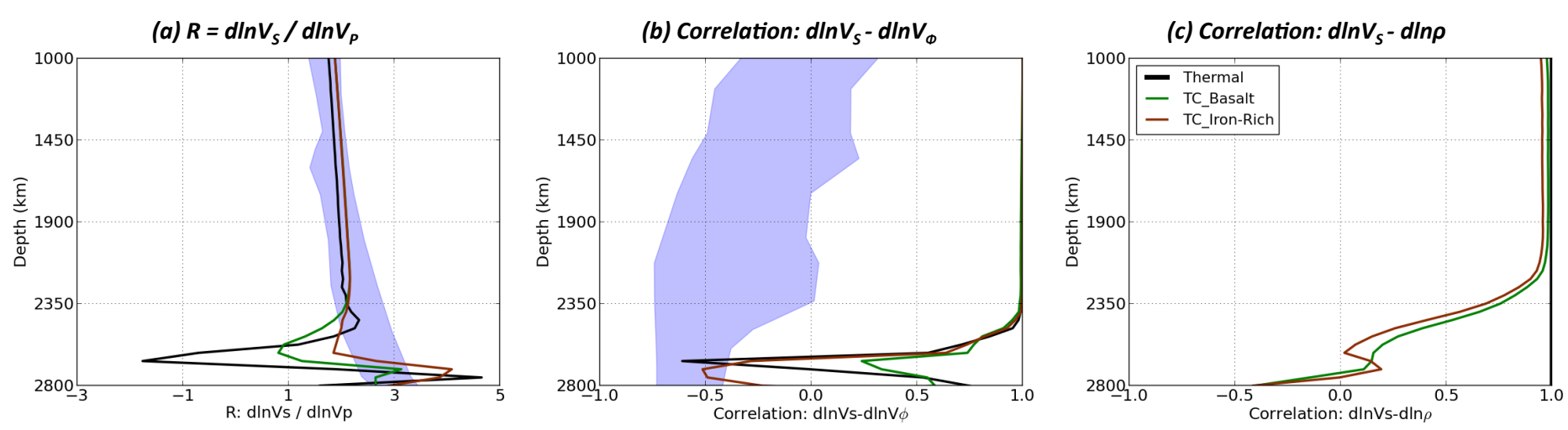

Figure 9: (a) The seismic ratio, $R=\mathrm{d} \ln \mathrm{V}_{S} / \mathrm{d} \ln \mathrm{V}_{P}$, as a function of depth, for all models, compared to seismological observations (shaded blue region: Robertson and Woodhouse, 1995; Su and Dziewonski, 1997; Kennett et al., 1998; Masters et al., 2000; Saltzer et al., 2001; Karato and Karki, 2001; Ritsema and van Heijst, 2002). $R$ is calculated by taking the ratio of all grid nodes with non-zero values of both compressional and shear-wave velocity perturbations. A histogram of these nodal values is made and the median value chosen at each depth (following Masters et al., 2000). Unlike mean values, medians are not biased by relatively local regions with extreme values of $R$; (b) The correlation of $\mathrm{d} l n \mathrm{~V}_{S}-\mathrm{d} l n \mathrm{~V}_{\phi}$ as a function of depth, compared to seismological observations (e.g. Su and Dziewonski, 1997; Masters et al., 2000); (c) The correlation of $\mathrm{d} l n \mathrm{~V}_{S^{-}}$ $\mathrm{d} \ln \rho$ as a function of depth. Note that our models have not been post-processed to account for the limited resolution and non-uniqueness inherent to the seismic data and, hence, models and data are not directly comparable. Nonetheless, models predict highly-variable $R$ and anti-correlations between bulk-sound and shear velocity only in the post-perovskite stability field. Furthermore, only thermo-chemical models produce an anti-correlation between $\operatorname{dn}_{\ln } \mathrm{V}_{S}$ and density (the purely thermal model predicts radially averaged correlations of 1 , even within the post-perovskite stability field).

and, hence, higher $R$ (e.g. Wookey et al., 2005; Ammann et al., 2010; Stixrude and Lithgow-Bertelloni, 2011). It remains to be tested how such $R$ values, which also display strong lateral variations (Davies et al., 2012), would be resolved in long-wavelength seismic images. However, it is clear that in the presence of lower-mantle phase transformations, elevated $R$ does not necessarily imply chemical heterogeneity.

The deep mantle anti-correlation between shear-wave velocity anomalies and bulk-sound velocity anomalies that is imaged by several studies (e.g. Su and Dziewonski, 1997; Masters et al., 2000) is closely related to high $R$. A smaller signature in $\mathrm{V}_{P}$ than $\mathrm{V}_{S}$ implies that the bulk modulus is less affected than, or affected in the opposite way from, the shear modulus by the physical properties of LLSVPs. Bulk-sound velocity is a factor of 2-4 less sensitive to temperature than $\mathrm{V}_{S}$ (e.g. Karato and Karki, 2001; Cobden et al., 2009). However, high temperatures do lower both velocities and, hence, cannot explain the anti-correlation between bulk-sound and shear-wave velocity. As such, the imaging of anti-correlated bulk and shear-wave velocity anomalies inside LLSVPs has been taken as a strong indication for compositional heterogeneity. However, relative to perovskite, post-perovskite has a decreased bulk modulus but an increased shear modulus and, hence, this transition can also lead to anti-correlated $\mathrm{V}_{S}$ and $\mathrm{V}_{\phi}$ (e.g. Wookey et al., 2005; Ammann et al., 2010; Stixrude and Lithgow-Bertelloni, 2011), as illustrated by our models in Fig. 6 and 9(b).

Significantly, there are very few compositions that have a high density (necessary to generate thermochemical piles) and opposite effects on bulk and shear moduli (e.g. Karato and Karki, 2001; Cobden et al., 
2009). The compositions examined herein do not do so at the temperature anomalies predicted. High iron content increases density but substantially lowers both moduli (e.g. Karato and Karki, 2001; Trampert et al., 2001; Cobden et al., 2009; Stixrude and Lithgow-Bertelloni, 2011). The presence of Ca-perovskite and stishovite in basaltic compositions increases density and shear modulus, and only has a minor effect on bulk modulus, resulting in faster shear-wave velocities than pyrolite and slightly slower bulk-sound velocities (Stixrude and Lithgow-Bertelloni, 2011). At mildly increased temperatures, this could lead to fast $\mathrm{V}_{S}$ and slow $\mathrm{V}_{\phi}$, an anti-correlation that is opposite in sign to what is observed (Deschamps et al., 2012). However, at the temperature anomalies of 1000-1200 K that are predicted inside our thermo-chemical piles, thermal effects easily outweigh a basalt's intrinsic compositional signature, particularly when accounting for anelasticity. To reproduce imaged anti-correlations, compositions that are substantially enriched in silica, which increases bulk-sound velocities much more than it does shear-wave velocity, as well as in iron, thus producing high density, have been proposed (e.g. Trampert et al., 2004; Mosca et al., 2012; Deschamps et al., 2012). It remains to be evaluated how such a composition could evolve. For example, experimental data indicates that cumulates from a magma ocean may be silica rich but will, most likely, have a low iron content and, hence, density (e.g. Walter et al., 2004).

Finally, it should be noted that there is substantial disagreement between different seismic models on the depth (Fig. 9b), geographic location, extent and even existence of the shear-bulk-sound-velocity anticorrelation (e.g. Su and Dziewonski, 1997; Kennett et al., 1998; Masters et al., 2000). For example, the study of Masters et al. (2000), which includes a wide range of data sensitive to deep mantle structure, shows a deep mantle anti-correlation that not only occurs inside LLSVPs, but also beneath the Americas and South-

East Asia. Some studies question whether the seismic data require an anti-correlation (e.g. Malcolm and Trampert, 2011; Schuberth et al., 2012). We note that the partial correlation between bulk-sound and shearwave velocities inferred from imaged seismic structure (Fig. 9b) may be a consequence of different seismic resolution and sensitivities for $P$ and $S$ waves, as one would expect both structures to be differently scaled versions of the same underlying physical structure and, accordingly, either be correlated or anti-correlated.

\subsection{Density-shear velocity anti-correlation}

A number of studies have inferred an anti-correlation between low shear-wave velocity anomalies and high density anomalies inside (and outside) LLSVPs, from combined inversion of seismic and geoid data (e.g. Ishii and Tromp, 1999; Trampert et al., 2004; Simmons et al., 2010; Mosca et al., 2012). Indeed, such an anti-correlation can only be explained by the presence of a compositionally distinct component and not by variations in temperature or phase, as illustrated in Fig. 9(c), where shear-wave velocity and density 
anomalies are fully correlated in the absence of chemical heterogeneity. However, there has been significant debate on whether lowermost mantle density heterogeneity is resolvable by the available data (e.g. Romanowicz, 2001; Masters and Gubbins, 2003). Furthermore, the positive geoid signature observed above LLSVPs requires that, if a dense chemical component is present, the overlying mantle's net buoyancy masks this signature at the surface (e.g. Gurnis et al., 2000; Ricard et al., 2006).

\subsection{1-D reference model biases}

\subsubsection{Differences seismic and physical reference models}

The seismic structure of Earth's mantle is predominantly 1-D. At depths away from phase transitions, below the lithosphere and above D", lateral variations in seismic velocity constitute only a few percent deviation from the mantle's spherical average. A vigorously convecting isochemical mantle, subject to internal heating, is expected to have a subadiabatic geotherm (e.g. Jeanloz and Morris, 1987; Bunge, 2005; Leng and Zhong, 2008) and a pyrolitic (MORB-source) composition (e.g. McDonough and Sun, 1995). Global seismic reference structures, such as PREM and AK135 (e.g. Dziewonski and Anderson, 1981; Kennett et al., 1995), share many of the features predicted from such a reference physical profile, with jumps at depths where phase transitions are expected and a smooth lower-mantle velocity-depth profile (Fig. 10b).

However, there are systematic differences between the tightly constrained seismic reference profiles and those predicted from pyrolitic, subadiabatic physical structures, which exceed our current best estimates for uncertainties in mineral physics parameters and the mantle's equation of state (e.g. Cammarano et al., 2005; Cobden et al., 2009). These include differences in average upper-mantle velocities and jumps in the transition zone (Fig. 10b), which have been attributed to compositional gradients (1-D layering or resulting from 3-D heterogeneity)(e.g. Duffy and Anderson, 1989; Cammarano and Romanowicz, 2007; Cobden et al., 2008), or seismic imaging biases (e.g. Davies and Bunge, 2001; Styles et al., 2011, and discussion below). Most relevant for this paper is that the seismic velocity gradients $\left(\mathrm{dV}_{P . S} / \mathrm{dz}\right)$ below $\sim 1500 \mathrm{~km}$ depth are consistently lower than those predicted from adiabatic to subadiabatic physical models (e.g. Cobden et al., 2009) (Fig. 10c). This discrepancy has been interpreted as the result of either superadiabatic temperature gradients and/or variations in composition as a function of depth (e.g. da Silva et al., 2000; Deschamps and Trampert, 2004; Matas et al., 2007; Khan et al., 2008; Cobden et al., 2009). For example, profiles where temperatures exceed the mantle adiabat by at least 200-400 K by $2500 \mathrm{~km}$ depth (such as those labeled +400 $\mathrm{K}$ and $+800 \mathrm{~K}$ in Fig. 10) can match the observed seismic gradients within the uncertainties. However, global compositional stratification is unlikely, given the absence of seismic discontinuities away from those expected for known phase transitions and evidence of slabs sinking into the lowermost mantle (e.g. Grand 


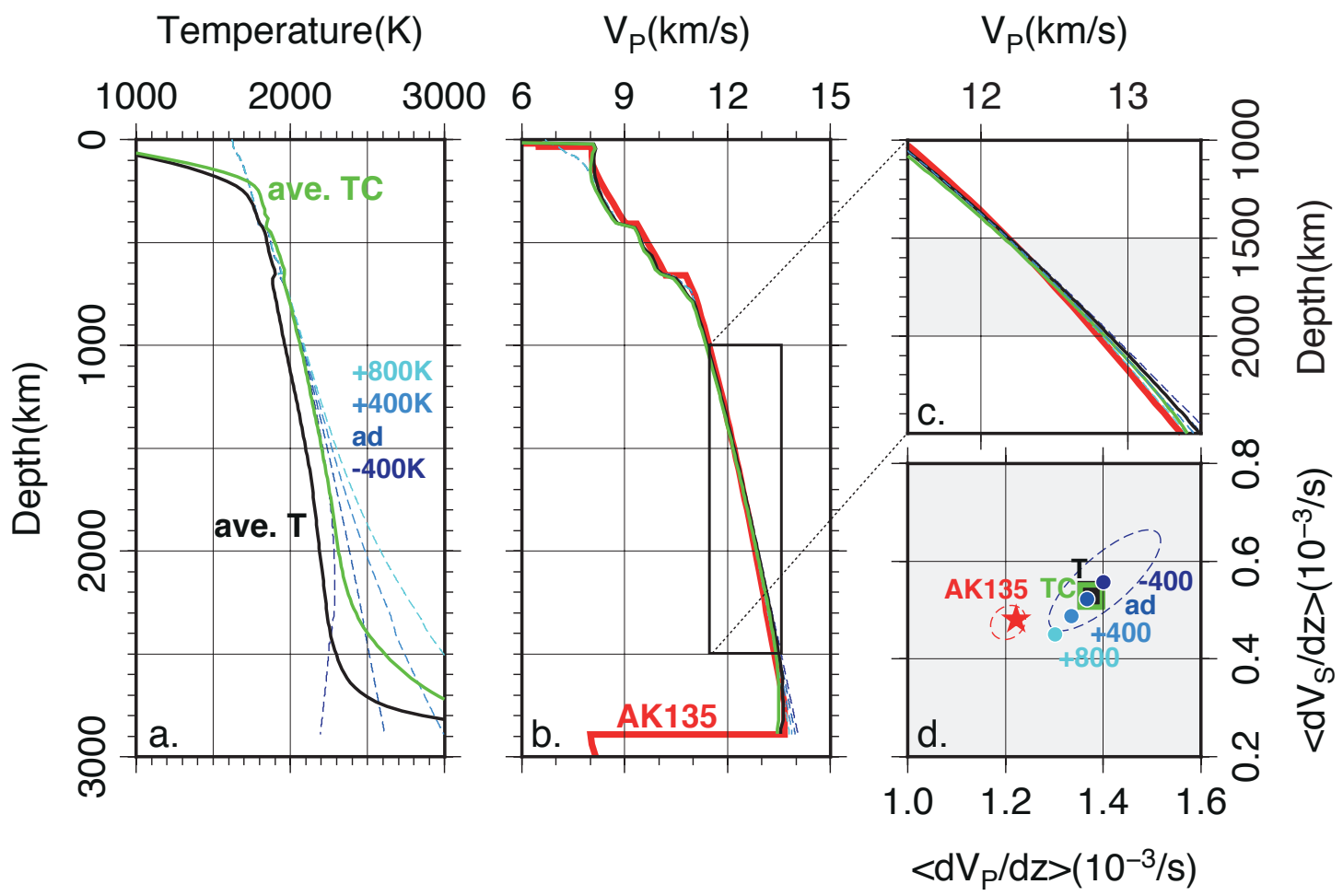

Figure 10: Comparison of synthetic 1-D P-velocity mantle structures with seismic model AK135 (Kennett et al., 1995): (a) A range of possible mantle geotherms: average of our thermal (black) and basaltic thermo-chemical (green) models, and a set of 1-D structures with MORB-source surface temperatures of $1350^{\circ} \mathrm{C}$, ranging from subadiabatic (dark blue: $-400 \mathrm{~K}$ by $2890 \mathrm{~km}$ depth) to strongly superadiabatic (cyan: $+400 \mathrm{~K}$ and $+800 \mathrm{~K}$ at $2890 \mathrm{~km} \mathrm{depth);} \mathrm{(b)} \mathrm{Compressional} \mathrm{velocity} \mathrm{for} \mathrm{the}$ thermal profiles from a, compared with AK135 (red) - note that the uncertainty in global seismic models is no more than the width of the red line; (c) Zoom of lower-mantle $\mathrm{V}_{P}$ between 1000 and $2500 \mathrm{~km}$ depth, illustrating the systematic mismatch in gradient between seismic reference models and our mantle geotherms; (d) averaged $\mathrm{V}_{P}$-depth gradients vs. averaged $\mathrm{V}_{S}$-depth gradients, between 1500 and $2000 \mathrm{~km}$ depth, for the range of models shown in a. The dashed red line comprises a range of published seismic models including PREM (Dziewonski and Anderson, 1981). The dashed blue line accounts for elastic parameter uncertainties, as computed by Cobden et al. (2009), plotted around the subadiabatic model. Although gradient mismatches between averaged 3-D models, or subadiabatic mantle and seismic models seem subtle, they fall consistently outside of the seismic and mineral physics uncertainties (Cobden et al., 2009). The differences are even more apparent in traveltime calculations (Fig. 11d).

et al., 1997; van der Hilst et al., 1997; Tackley, 2002). Hence, it has been proposed that the compositional gradients arise as a consequence of 3-D heterogeneity, in the form of discontinuous piles at the mantle's base (e.g. Cobden et al., 2009). Furthermore, without stratification, chemically stabilised piles may be required to sustain a net super-adiabatic gradient (Cobden et al., 2009), because as noted previously, a vigorously convecting isochemical mantle would generate a subadiabatic mantle geotherm (e.g. Bunge, 2005). As the sensitivity of seismic velocity to temperature increases at higher temperatures (due to anelasticity), the presence of hot chemical piles in the lowermost mantle may bias the average seen by seismic waves away from the actual physical average. 


\subsubsection{3-D structure biases to average mantle structure?}

Using the dynamic models presented above, we test whether or not thermal or thermo-chemical LLSVPs can bias the mantle's radially averaged seismic structure away from that of the mantle's radially averaged physical structure. In a previous paper, we compared seismic velocities for the average radial physical state with laterally averaged seismic velocities (Styles et al., 2011). We found that thermal or thermo-chemical structure that generates velocity anomalies of the same order as those inferred from seismic tomography yields an averaged lower-mantle velocity structure that matches the actual average to within $0.1 \%$. This difference falls within the uncertainties in seismic reference profiles and, hence, cannot account for the difference between seismically imaged structure and predicted seismic structure from a physical reference model.

However, the study by Styles et al. (2011) assumed uniform seismic sampling of mantle structure. Here, we present the results of a test of seismic sampling effects, using traveltimes for direct $P$ waves. This is an extreme case, as seismic reference models are derived from a range of body-wave phases, and some models, such as PREM and AK135-f, also include normal modes (which have global sensitivity), whilst a weighting or averaging of data is often undertaken to reduce any geographic bias. We perform a relatively simple calculation, where ray paths are computed through a 1-D Earth (the model average) using TauP (Crotwell et al., 1999), whilst traveltime integration along these ray paths is done through the full 3-D structure, with CRUST2.0 (Bassin et al., 2000) superimposed above. Full 3-D ray tracing would be more accurate, but several studies have found it to have a relatively small effect and, hence, it is not commonly done in global tomographic studies (e.g. Bijwaard and Spakman, 2000; Simmons et al., 2011). Inaccurate rays can lead to underestimates of the influence of small features (in particular slabs) (Zhao and Lei, 2003), but we verified that the (relatively broad) model slabs are sampled by our ray geometries. Finite-frequency effects may also influence traveltimes, but these are small for the high-frequency direct $P$-wave data considered here (e.g. Montelli et al., 2004). Furthermore, we find that the predicted geographic bias is so much smaller than the discrepancy between seismic and physical reference models, that improved traveltime calculations are unlikely to change our conclusions.

Our tests demonstrate that biased geographical sampling has some systematic effects. To illustrate these, in Fig. 11(b/c) synthetic traveltime anomalies and their means are plotted, as a function of epicentral distance, all relative to the traveltime predicted for the mean velocity structure. For comparison, Fig. 11(a) shows the scatter of ISC traveltimes around their mean, which is similar to the scatter around AK135, a model that was derived to fit this data (plus additional phases). Fig. 11(d) shows the traveltime discrepancies between the seismic and physical reference models, including the thermal and basaltic thermo-chemical 
(a) data-mean
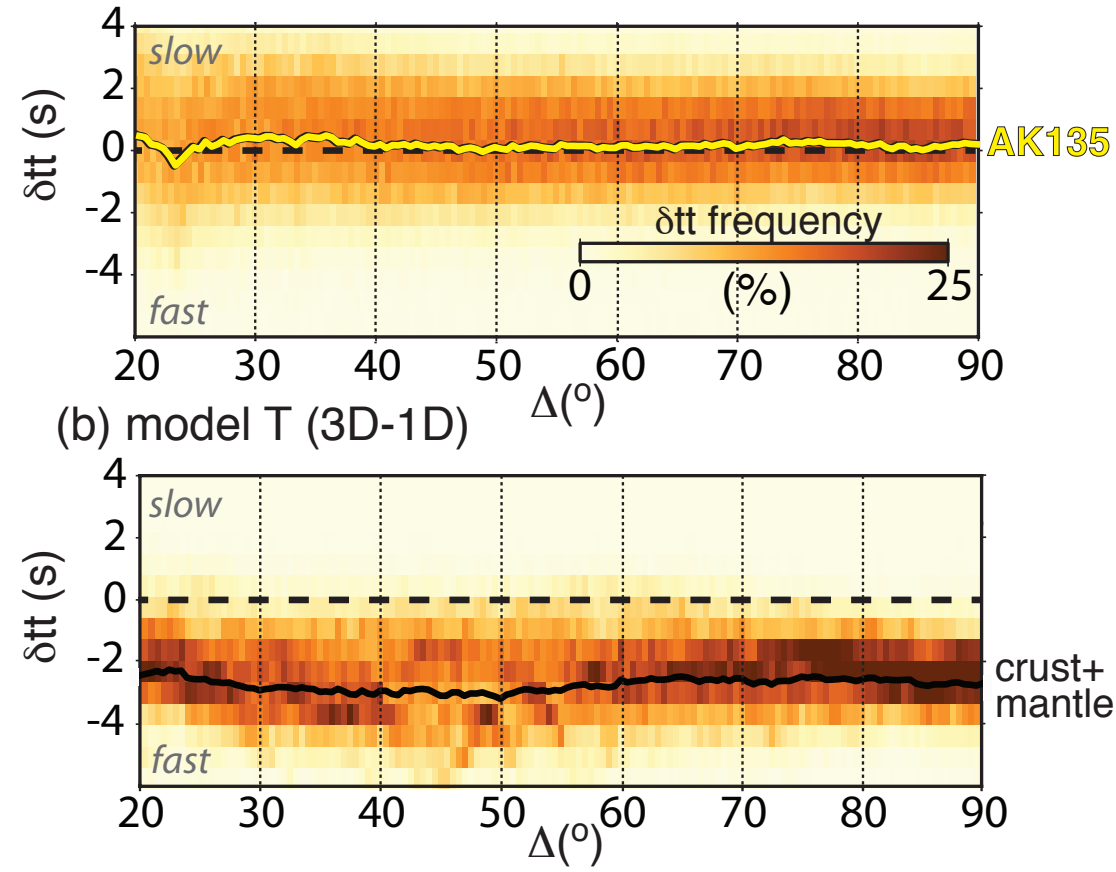

(c) model TC (3D-1D)
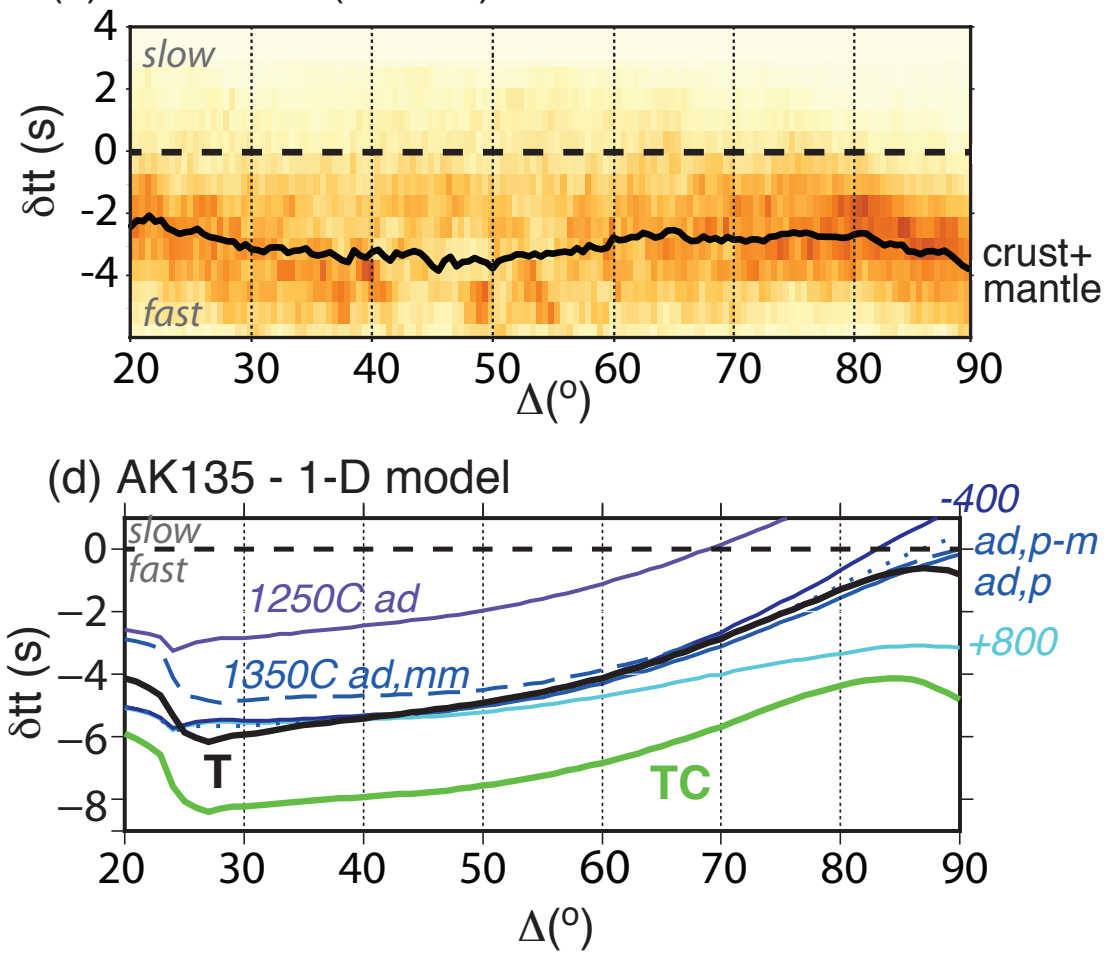

Figure 11: Comparison of modelled geographic traveltime biases with scatter in ISC traveltime data and traveltime differences between physical and seismic reference model, all plotted as a function of epicentral distance $\Delta$ : (a) distribution of ISC direct $P$ traveltime anomalies (orange) relative to catalog mean, plus difference between catalog mean and AK135 (in yellow); (b,c) Synthetic $P$ traveltime anomalies (orange) relative to traveltimes through 1-D average model structure. Mean anomaly (due to 3D crust and mantle structure) in bold black. The offset between the 3-D mean traveltime and the time through the average 1-D structure is due to geographic sampling bias. This bias is fast throughout and mainly accumulated in the crust and shallow upper mantle $\left(\Delta<20^{\circ}\right)$; (d) Traveltimes of synthetic velocity models from Fig. 10 relative to those for AK135 (Kennett et al., 1995), where T (black) and TC (green) denote the average of 3-D thermal and basaltic thermo-chemical models, respectively, $1250^{\circ} \mathrm{C}$ ad (purple) - adiabatic profile with surface $\mathrm{T}$ of $1250^{\circ} \mathrm{C}$ and pyrolitic composition, $1350^{\circ} \mathrm{C}$ surface $\mathrm{T}$ profiles (shades of blue) - pyrolitic composition (solid lines): $-400^{\circ}$ subadiabatic (dark blue), $+800^{\circ}$ superadiabatic (cyan) and adiabatic (blue), adiabatic mechanical mixture (blue, dashed), adiabatic pyrolite to MORB compositional gradient (blue, dotted). Variations in the discrepancy between physical models and AK135 as a function of $\Delta$ clearly exceed the variation expected from geographical bias. 
models examined herein and a few different adiabatic cases.

The main geographic bias is accrued in the lithosphere, above 200-300 km depth (epicentral distances $<15^{\circ}$ ), where the distribution of sources and receivers leads to preferential sampling of continental keels and subducting slabs. This is a well-known bias (e.g. Davies and Bunge, 2001), which means that the sampled Earth looks $\sim 2$ seconds faster than the actual reference structure. Below this depth, to epicentral distances of $\sim 50^{\circ}$, the direct $P$ waves preferentially sample slabs, leading to a further increase in the fast bias of imaged mantle structure, but only 0.5 seconds. Below about 1200-1500 km depth (epicentral distances $>50^{\circ}$ ), the fast bias decreases as rays sample more and more background mantle material. Note that since LLSVPs are poorly sampled by this set of rays, they have little effect on the traveltime bias, whether they are of thermal or thermo-chemical origin. Indeed, the fast bias is shown to increase further in the lowermost mantle, where rays preferentially sample faster material away from LLSVPs. As velocity anomalies are larger in the thermo-chemical model, this lowermost mantle increase in fast bias is more prominent. Interestingly, the increase and subsequent decrease of the fast slab bias through the mid-mantle has a similar trend as the difference between seismic and physical reference models. However, the resulting variations in traveltimes due to geographically biased sampling (Fig. 11b/c) are 3-8 times smaller $\left(\sim 0.5\right.$ seconds from $\Delta=40^{\circ}$ to $\left.70^{\circ}\right)$ than the difference between seismic and physical models $\left(\sim 2\right.$ seconds, from $\Delta=40^{\circ}$ to $70^{\circ}$, Fig. $\left.11 d\right)$ and, thus, cannot reconcile the two.

\subsubsection{1-D Reference Models Summary}

Mismatches between seismic and physical reference models likely cannot give further insight into the thermal or thermo-chemical nature of LLSVPs. Alternative 1-D effects that have been proposed to influence deep mantle seismic structure, such as the Fe-spin transition (e.g. Badro et al., 2003), would not lead to the systematic difference between seismic and physical models that varies smoothly with depth (Cammarano et al., 2010). Rather, the mismatch may indicate that uncertainties in the mineral physic data, in particular, the pressure and temperature-dependence of the shear modulus under deep mantle conditions (e.g. Jackson, 1998; Deschamps and Trampert, 2004; Matas et al., 2007), may exceed those previously considered (e.g. Cammarano et al., 2005; Cobden et al., 2009).

\subsection{The spatial relation between hotspots, reconstructed LIPs and LLSVPs}

Inferred spatial correlations between the reconstructed eruption sites of LIPs and surface hotspot locations with LLSVP margins at depth are regularly invoked as firm evidence for the thermo-chemical nature of LLSVPs (e.g. Thorne et al., 2004; Torsvik et al., 2006; Burke et al., 2008; Torsvik et al., 2008b, 2010). These 

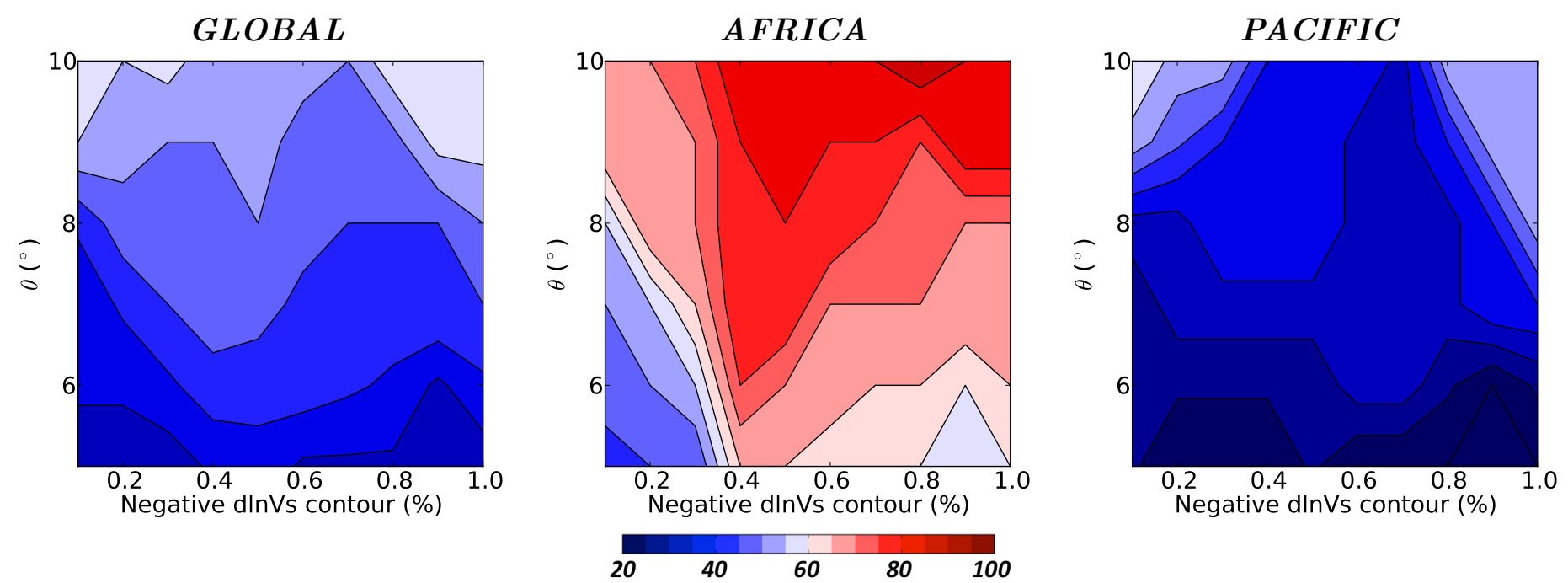

Figure 12: The percentage of hotspots from the catalogue of Steinberger (2000), that are located within an angular distance $(\theta)$ of LLSVP margins, at $2800 \mathrm{~km}$ depth, as delineated by a specific negative $\operatorname{dn} V_{S}$ contour in the SMEAN tomographic model (from Davies et al., submitted). Results are presented globally and regionally for hotspots that are located in the African and Pacific domains. At $\theta=10^{\circ}$ and $\mathrm{d} \ln V_{S}=-1.0 \%$, the result of Torsvik et al. (2006) is reproduced, with $\sim 55 \%$ of hotspots located above LLSVP margins. This spatial correlation, however, is reduced to $<30 \%$ at lower $\theta$ values and shows substantial regional variability between the African and Pacific domains, with strong correlations generally observed for the former $(>80 \%$, at $\left.\theta \geq 8^{\circ}\right)$ and weak correlations for the latter $(<50 \%$, even at the highest $\theta$ values). This is consistent with the map presented in Fig. 3, which clearly shows that hotspots occur both above the interior (high $\operatorname{dn} V_{S}$ amplitudes) and above the margins (low $\operatorname{d} \ln V_{S}$ amplitudes) of the Pacific LLSVP.

studies attribute the plume localisation implied by this observation to the interaction of mantle flow with stable, high-density piles, leading to preferential plume initiation near pile margins (e.g. Tan et al., 2011; Steinberger and Torsvik, 2012).

However, it should be noted that if piles exist on the spatial scale implied by LLSVPs and are able to remain sequestered in the deep mantle for hundreds of millions of years, they will build up substantial excess temperatures, when compared to ambient mantle (Davies et al., 2012). Internal upwellings, in addition to those at the margins, are therefore required if piles are to release their heat (e.g. Jellinek and Manga, 2002). Furthermore, even in purely thermal models, the interaction of downwellings with the mantle's lower thermal boundary layer reduces plume initiation times, facilitating plume initiation at the leading edge of deep-mantle slabs (e.g. Schaeffer and Manga, 2001; Tan et al., 2002; Goes et al., 2004).

Perhaps most significantly, the hypothesised spatial correlation between the surface expression of mantle plumes and LLSVP margins has recently been questioned. Using Monte-Carlo based statistical analyses, Austermann et al. (2014) demonstrate that, with the available global sample of reconstructed LIPs, it is not possible to discriminate between a spatial correlation with LLSVP margins or their interiors. Furthermore, Fig. 12 displays results from straightforward analysis of the correlation between hotspots and LLSVP margins, following the approach of Torsvik et al. (2006), but illustrating the sensitivity to the dln $V_{S} \operatorname{contour}$ used to delineate the LLSVP margin and the maximum plume tilt angle, $\theta$. This confirms that hotspots are 
preferentially located above the margins of the African LLSVP. However, this is not the case within the Pacific domain, where hotspots show no clear preference for the underlying LLSVP margin: the correlation between hotspots and LLSVP margins is not a global feature. Further (statistical) analyses demonstrate that this difference also applies to reconstructed LIPs, and is likely a simple consequence of the differential geometries of the elongated African LLSVP and its more rounded Pacific counterpart (Davies et al., submitted).

We emphasise that these results do not rule out the presence of dense thermo-chemical piles in the deep mantle beneath Africa and the Pacific. However, they do imply that surface hotspot locations and the reconstructed eruption sites of LIPs can not be invoked as an argument in their favour.

\section{Summary}

Of the nine seismic arguments commonly invoked as evidence that LLSVPs constitute thermo-chemical piles, our analyses suggest that only an anti-correlation between shear-wave velocity anomalies and density anomalies would provide unambiguous evidence for the presence of dense chemical heterogeneity. Sphericallyaveraged lower-mantle seismic velocity-depth gradients are not sensitive to LLSVP structure, whilst all other constraints, including LLSVP morphology, shear-wave velocity amplitudes and gradients, (relative) variation of shear, compressional and bulk-sound speeds, and the relationship between LLSVPs and the distribution of intraplate volcanism, are equally well explained with thermal and thermo-chemical models. Although an anti-correlation between shear-wave velocity anomalies and density anomalies has been found in some studies (e.g. Ishii and Tromp, 1999; Trampert et al., 2004), our ability to resolve lower-mantle density heterogeneity is debated (e.g. Romanowicz, 2001; Masters and Gubbins, 2003). Furthermore, imaged distributions of lower-mantle shear-wave velocity anomalies allow, at most, a very low volume fraction $(<1 \%$ of the mantle's volume) of dense chemical heterogeneity in deep mantle piles. Whether or not such low volume fractions are detectable remains to be seen. However, such heterogeneity, although geochemically significant, would exert control on lowermost mantle dynamics and its large-scale geophysical structure.

\section{Acknowledgments}

DRD was partially funded by a Fellowship from NERC (NE/H015329/1). Numerical simulations were undertaken on: (i) HECToR, the UK's national high-performance computing service, which is provided by UoE HPCx Ltd at the University of Edinburgh, Cray Inc and NAG Ltd, and funded by the Office of Science and Technology through EPSRC's High End Computing Program; and (ii) the NCI National Facility in Canberra, Australia, which is supported by the Australian Commonwealth Government. Authors would like 
to thank: Lars Stixrude and Carolina Lithgow-Bertelloni for providing the lookup tables used in converting models from physical structure to seismic velocity; and Jeroen Ritsema for providing S40RTS' resolution operator. Authors benefited from discussion with Huw Davies, Jeroen Ritsema, Hans-Peter Bunge, Bernhard Schuberth, Julie Prytulak, Brian Kennett, Ian Campbell and Geoff Davies. Authors would like to thank two anonymous reviewers for constructive comments on this manuscript, as well as Frederic Deschamps for editorial input.

\section{References}

D. Alfè, M. J. Gillan, and G. D. Price. Temperature and composition of the Earth's core. Contemp. Phys., 48:63-80, 2007. doi: 10.1080/00107510701529653.

C. Allègre, G. Manhes, and E. Lewin. Chemical composition of the Earth and the volatility control on planetary genetics. Earth Planet. Sci. Lett., 185:49-69, 2001. doi: 10.1016/S0012-821X(00)00359-9.

C. J Allègre, O. Brevart, B. Dupre, and J. F. Minster. Isotopic and chemical effects produced in a continuously differentiating convecting Earth mantle. Phil. Trans. R. Soc. London, Ser. A, 297:447-477, 1980. doi: 10.1098/rsta.1980.0225.

C. J. Allègre, T. Staudacher, and P. Sarda. Rare gas systematics: formation of the atmosphere, evolution and structure of the Earth's mantle. Earth Planet. Sci. Lett., 81:127-150, 1987. doi: 10.1016/0012821X(87)90151-8.

C. J. Allègre, A. W. Hofmann, and R. K. O'Nions. The Argon constraints on mantle structure. Geophys. Res. Lett., 23:3555-3557, 1996. doi: 10.1029/96GL03373.

M. W. Ammann, J. P. Brodholt, J. Wookey, and D. P. Dobson. First-principles constraints on diffusion in lower-mantle minerals and a weak D" layer. Nature, 465:251-267, 2010. doi: 10.1038/nature09052.

D.L. Anderson. Hotspots, polar wander, Mesozoic convection and the geoid. Nature, 297:391-393, 1982. doi: $10.1038 / 297391 \mathrm{a} 0$.

J. Austermann, B.T. Kaye, J.X. Mitrovica, and P. Huybers. A statistical analysis of the correlation between large igneous provinces and lower mantle seismic structure. Geophys. J. Int., 2014. doi: 10.1093/gji/ggt500.

J. Badro, G. Fiquet, F. Guyot, J.-P. Rueff, V. V. Struzhkin, G. Vankó, and G. Monaco. Iron partitioning in Earth's mantle: toward a deep lower-mantle discontinuity. Science, 300:789-791, 2003. doi: 10.1126/science.1081311.

C. Bassin, G. Laske, and G. Masters. The Current Limits of resolution for surface wave tomography in North America. EOS Trans. AGU., 81:F897, 2000.

J. R. Baumgardner. Three-dimensional treatment of convective flow in the Earth's mantle. J. Stat. Phys., 39:501-511, 1985. doi: 10.1007/BF01008348.

T. W. Becker and L. Boschi. A comparison of tomographic and geodynamic mantle models. Geochem. Geophys. Geosys., 3:2001GC000168, 2002. doi: 10.129/2001GC000168. 
H. Bijwaard and W. Spakman. Non-linear global P-wave tomography by iterated linearized inversion. Geophys. J. Int., 141:71-82, 2000. doi: 10.1046/j.1365-246X.2000.00053.x.

R. Boehler. High-pressure experiments and the phase diagram of lower mantle and core materials. Rev. Geophys., 38:221-245, 2000. doi: 10.1029/1998RG000053.

D. J. Bower, M. Gurnis, and M. Seton. Lower mantle structure from paleogeographically constrained dynamic Earth models. Geochem. Geophys. Geosys., 14:44-63, 2013. doi: 10.1029/2012GC004267.

M. Boyet and R. W. Carlson. ${ }^{142} \mathrm{Nd}$ evidence for early (4.53 Ga) global differentiation of the silicate Earth. Science, 309:576-581, 2005.

M. Boyet and R. W. Carlson. A new geochemical model for the Earth's mantle inferred from ${ }^{146} \mathrm{Sm} /{ }^{142} \mathrm{Nd}$ systematics. Earth Planet. Sci. Lett., 250:254-268, 2006.

J. P. Brandenburg and P. E. van Keken. Deep storage of oceanic crust in a vigorously convecting mantle. J. Geophys. Res., 112:B06403, 2007. doi: 10.1029/2006JB004813.

J. P. Brandenburg, E. H. Hauri, P. E. van Keken, and C. J. Ballentine. A multiple-system study of the geochemical evolution of the mantle with force-balanced plates and thermochemical effects. Earth Planet. Sci. Lett., 276:1-13, 2008. doi: 10.1016/j.epsl.2008.08.027.

J. P. Brodholt, G. Hellfrich, and J. Trampert. Chemical versus thermal heterogeneity in the lower mantle: the most likely role of anelasticity. Earth Planet. Sci. Lett., 262:429-437, 2007. doi: 10.1016/j.epsl.2007.07.054.

J.M. Brown and T.J Shankland. Thermodynamic parameters in the Earth as determined from seismic profiles. Geophys. J. R. Astron. Soc., 66:579-596, 1981.

Bruce A. Buffett. Estimates of heat flow in the deep mantle based on the power requirements for the geodynamo. Geophys. Res. Lett., 29:4 PP., 2002. doi: 200210.1029/2001GL014649.

A. L. Bull, A. K. McNamara, and J. Ritsema. Synthetic tomography of plume clusters and thermochemical piles. Earth Planet. Sci Lett., 278:152-156, 2009. doi: 10.1016/j.epsl.2008.11.018.

H.-P. Bunge. Low plume excess temperature and high core heat flux inferred from non-adiabatic geotherms in internally heated mantle circulation models. Phys. Earth Planet. Int., 153:3-10, 2005. doi: $10.1016 /$ j.pepi.2005.03.017.

H.-P. Bunge, M. A. Richards, and J. R. Baumgardner. A sensitivity study of 3-D-spherical mantle convection at $10^{8}$ Rayleigh number: effects of depth-dependent viscosity, heating mode and an endothermic phase change. J. Geophys. Res., 102:11991-12007, 1997. doi: 10.1029/96JB03806.

H.-P. Bunge, M. A. Richards, and J. R. Baumgardner. Mantle circulation models with sequential dataassimilation: inferring present-day mantle structure from plate motion histories. Phil. Trans. R. Soc. London, Set. A, 360:2545-2567, 2002. doi: 10.1098/rsta.2002.1080.

K. Burke, B. Steinberger, T. H. Torsvik, and M. A. Smethurst. Plume generation zones at the margins of large low shear velocity provinces on the core-mantle-boundary. Earth Planet. Sci. Lett., 265:49-60, 2008. doi: 10.1016/j.epsl.2007.09.042.

F. Cammarano and B. Romanowicz. Insights into the nature of the transition zone from physically constrained inversion of long period seismic data. PNAS-High Pressure Geoscience, 104:9139-9144, 2007. 
F. Cammarano, S. Goes, A. Deuss, and D. Giardini. Is a pyrolitic adiabatic mantle compatible with seismic data? Earth Planet. Sci. Lett., 232:227-243, 2005.

F. Cammarano, H. Marquardt, S. Speziale, and P. J. Tackley. Role of iron-spin transition in ferropericlase on seismic interpretation: A broad thermochemical transition in the mid mantle? Geophys. Res. Lett., 37, 2010. doi: 10.1029/2009GL041583.

I. H. Campbell and R. W. Griffiths. The changing nature of mantle hotspots through time: implications for the geochemical evolution of the mantle. J. Geology, 100:497-523, 1992.

I. H. Campbell and H. C. O'Neill. Evidence against a Chondritic Earth. Nature, 483:553-558, 2012. doi: 10.1038/nature10901.

G. Caro and B. Bourdon. Non-chondritic Sm/Nd ratio in the terrestrial planets: consequences for the geochemical evolution of the mantle-crust system. Geochim. Cosmochim. Acta., 74:3333-3349, 2010.

U. R. Christensen and A. W. Hofmann. Segregation of subducted oceanic crust in the mantle. J. Geophys. Res., 99:19867-19884, 1994.

L. Cobden, S. Goes, F. Cammarano, and J. A. D. Connolly. Thermochemical interpretation of onedimensional seismic reference models for the upper mantle: evidence for bias due to heterogeneity. Geophys. J. Int, 175:627-648, 2008. doi: 10.1111/j.1365-246X.2008.03903.x.

L. Cobden, S. Goes, M. Ravenna, E. Styles, F. Cammarano, K. Gallagher, and J. A. D. Connolly. Thermochemical interpretation of 1-D seismic data for the lower mantle: the significance of nonadiabatic thermal gradients and compositional heterogeneity. J. Geophys. Res., 114:B11309, 2009. doi: 10.1029/2008JB006262.

N. Coltice and Y. Ricard. Geochemical observations and one layer mantle convection. Earth Planet. Sci. Lett., 174:125-137, 1999.

H. P. Crotwell, T. J. Owens, and J. Ritsema. The TauP toolkit: Flexible seismic travel-time and ray-path utilities. Seism. Res. Lett., 70:154-160, 1999. doi: 10.1785/gssrl.70.2.154.

C. R. S. da Silva, R.M. Wentzcovitch, A. Patel, G.D. Price, and S.I. Karato. The composition and geotherm of the lower mantle: Constraints from the elasticity of silicate perovskite. Earth Planet. Sci. Lett., 118: 103-109, 2000. doi: 10.1016/S0031-9201(99)00133-8.

A. Davaille. Simultaneous generation of hotspots and superswells by convection in a heterogeneous planetary mantle. Nature, 402:756-760, 1999.

D. R. Davies and J. H. Davies. Thermally-driven mantle plumes reconcile multiple hotspot observations. Earth Planet. Sci. Lett., 278:50-54, 2009. doi: 10.1016/j.epsl.2008.11.027.

D. R. Davies, S. Goes, J. H. Davies, B. S. A. Schuberth, H.-P. Bunge, and J. Ritsema. Reconciling dynamic and seismic models of Earth's lower mantle: the dominant role of thermal heterogeneity. Earth Planet. Sci. Lett., 353-354:253-269, 2012. doi: 10.1016/j.epsl.2012.08.016.

D. R. Davies, J. H. Davies, P. C. Bollada, O. Hassan, K. Morgan, and P. Nithiarasu. A hierarchical mesh refinement technique for global 3D spherical mantle convection modelling. Geosci. Mod. Dev., 6:1095-1107, 2013. doi: 10.5194 /gmd-6-1095-2013. 
D. R. Davies, S. Goes, and M. Sambridge. On the relationship between volcanic hotspot locations, the reconstructed eruption sites of large igneous provinces and deep mantle seismic structure. Earth Planet. Sci. Lett., submitted.

G. F. Davies. Dynamic Earth: plates, plumes and mantle convection. Cambridge University Press, 1999. ISBN 9780521599337.

G. F. Davies. Reconciling the geophysical and geochemical mantles: plume flows, heterogeneities and disequilibrium. Geochem. Geophy. Geosyst., 10:Q10008, 2009. doi: 10.1029/2009GC002634.

G. F. Davies. Dynamical geochemistry of the mantle. Solid Earth, 2:159-189, 2011. doi: 10.5194/se-2-1592011.

J. H. Davies and H. P. Bunge. Seismically 'fast' geodynamic mantle models. Geophys. Res. Lett., 28:73-76, 2001.

N. de Koker. Thermal conductivity of $\mathrm{MgO}$ at high pressure: implications for the $\mathrm{D}^{\prime \prime}$ region. Earth Planet. Sci. Lett., 292:392-398, 2010.

F. Deschamps and P. J. Tackley. Exploring the model space of thermo-chemical convection: (i) principles and influence of the rheological parameters. Phys. Earth Planet. Int., 171:357-373, 2008.

F. Deschamps and P. J. Tackley. Searching for models of thermo-chemical convection that explain probabilistic tomography: (ii) influence of physical and compositional parameters. Phys. Earth Planet. Int., 176:1-18, 2009.

F. Deschamps and J. Trampert. Towards a lower mantle reference temperature and composition. Earth Planet. Sci. Lett., 222:161-175, 2004.

F. Deschamps, E. Kaminski, and P. J. Tackley. A deep mantle origin for the primitive signature of ocean island basalt. Nature Geo., 4:879-882, 2011. doi: 10.1038/NGEO1295.

F. Deschamps, L. Cobden, and P. J. Tackley. The primitive nature of large low shear-wave velocity provinces. Earth Planet. Sci. Lett., 349-350:198-208, 2012. doi: 10.1016/j.epsl.2012.07.012.

T. S. Duffy and D. L. Anderson. Seismic velocities in mantle minerals and the mineralogy of the upper mantle. J. Geophys. Res., 94(B2):1895-1912, 1989. doi: 10.1029/JB094iB02p01895.

R. A. Duncan and M. A. Richards. Hotspots, mantle plumes, flood basalts and true polar wander. Rev. Geophys., 29:31-50, 1991.

A. M. Dziewonski and D. L. Anderson. Preliminary reference Earth model. Phys. Earth. Planet. Int., 25: 297-356, 1981.

A. M. Dziewonski, B. H. Hager, and R. J. O'Connell. Large-scale heterogeneities in the lower mantle. J. Geophys. Res., 82:239-255, 1977.

A.M. Dziewonski, V. Lekic, and B.A. Romanowicz. Mantle anchor structure: An argument for bottom up tectonics. Earth Planet. Sci. Lett., 299:69-79, 2010.

A. M. Forte and J. X. Mitrovica. Deep-mantle high-viscosity flow and thermochemical structure inferred from seismic and geodynamic data. Nature, 410:1049-1056, 2001. 
Y. Fukao and M. Obayashi. Subducted slabs stagnant above, penetrating through and trapped below the 660 km discontinuity. J. Geophys. Res., 118:5920-5938, 2013. doi: 10.1002/2013JB010466.

F. Garel, S. Goes, D. R. Davies, J. H. Davies, S. C. Kramer, and C. R. Wilson. Interaction of subducted slabs with the mantle transition-zone: A regime diagram from 2-D thermo-mechanical models with a mobile trench and an overriding plate. Geochem. Geophys. Geosys., 15, 2014. doi: 10.1002/2014GC005257.

E. J. Garnero and A. K. McNamara. Structure and dynamics of Earth's lower mantle. Science, 320:626-628, 2008.

G. A. Glatzmaier and P. H. Roberts. A 3-D self-consistent computer simulation of a geomagnetic field reversal. Nature, 377:203-209, 1995.

S. Goes, F. Cammarano, and U. Hansen. Synthetic seismic signature of thermal mantle plumes. Earth Planet. Sci. Lett., 218:403-419, 2004. doi: 10.1016/S0012-821X(03)00680-0.

S. Grand, R. D. van der Hilst, and S. Widiyantoro. Global seismic tomography: a snapshot of mantle convection in the Earth. GSA Today, 7:1-7, 1997.

D. Gubbins, D. Alfè, G. Masters, G. D. Price, and M. Gillan. Gross thermodynamics of two-component core convection. Geophys. J. Int., 157:1407-1414, 2004. doi: 10.1111/j.1365-246X.2004.02219.x.

M. Gurnis, J. X. Mitrovica, J. Ritsema, and H. J. van Heijst. Constraining mantle density structure using geological evidence of surface uplift rates: the case of the African superplume. Geochem. Geophys. Geosys., 1:1999GC000035, 2000.

B. H. Hager, R. W. Clayton, M. A. Richards, R. P. Comer, and A. M. Dziewonski. Lower mantle heterogeneity, dynamic topography and the geoid. Nature, 313:541-545, 1985. doi: 10.1038/313541a0.

B. B. Hanan and D. W. Graham. Lead and helium isotopic evidence from oceanic basalts for a common deep source of mantle plumes. Science, 272:991-995, 1996. doi: 10.1126/science.272.5264.991.

Y. He and L. Wen. Structural features and shear-velocity structure of the 'Pacific anomaly'. J. Geophys. Res, 114:B02309, 2009. doi: 10.1029/2008JB005814.

J. W. Hernlund and C. Houser. On the statistical distribution of seismic velocities in Earth's deep mantle. Earth Planet. Sci. Lett., 265:423 - 437, 2008. doi: 10.1016/j.epsl.2007.10.042.

J. W. Hernlund, C. Thomas, and P. J. Tackley. A doubling of the post-perovskite phase boundary and structure of the Earth's lowermost mantle. Nature, 434:882-886, 2005.

A. W. Hofmann. Mantle geochemistry: the message from oceanic volcanism. Nature, 385:219-229, 1997. doi: $10.1038 / 385219 \mathrm{a} 0$.

A. W. Hofmann. Sampling mantle heterogeneity through oceanic basalts: isotopes and trace elements. In Treatise on Geochemistry, pages 61-101. Elsevier, 2003.

C. Houser, G. Masters, P. Shearer, and G. Laske. Shear and compressional velocity models of the mantle from cluster analysis of long-period waveforms. Geophys. J. Int, 174:195-212, 2008. doi: 10.1111/j.1365246X.2008.03763.x.

J. Huang and G. F. Davies. Stirring in three-dimensional mantle convection models and implications for geochemistry: Passive tracers. Geochem. Geophys. Geosyst., 8:Q03017, 2007a. doi: 10.1029/2006GC001312. 
J. Huang and G. F. Davies. Stirring in three-dimensional mantle convection models and implications for geochemistry: Heavy tracers. Geochem. Geophys. Geosyst., 8:Q07004, 2007b. doi: 10.1029/2007GC001621.

S. A. Hunt, D. R. Davies, A. M. Walker, R. J. McCormack, A. S. Wills, D. P. Dobson, and L. Li. On the increase in thermal diffusivity caused by the perovskite to post-perovskite phase transition and its implications for mantle dynamics. Earth Planet. Sci. Lett., 319:96-103, 2012. doi: 10.1016/j.epsl.2011.12.009.

M. Ishii and J. Tromp. Normal-mode and free-air gravity constraints on lateral variations in velocity and density of Earth's mantle. Science, 285:1231-1236, 1999. doi: 10.1126/science.285.5431.1231.

I. Jackson. Elasticity, composition and temperature of the Earth's lower mantle: a reappraisal. Geophys. J. Int, 134:291-311, 1998. doi: 10.1046/j.1365-246x.1998.00560.x.

M. G. Jackson and R. Carlson. An ancient recipe for flood basalt genesis. Nature, 476:316-319, 2011. doi: 10.1038/nature10326.

M. H. Jackson, R. Carlson, M. D. Kurz, P. D. Kempton, D. Francis, and J. Blusztajn. Evidence for the survival or the oldest terrestrial mantle reservoir. Nature, 466:853-856, 2010.

M. Javoy, E. Kaminski, F. Guyot, D. Andrault, C. Sanloup, M. Moreira, S. Labrosse, A. Jambon, P. Agrinier, A. Davaille, and C. Jaupart. The chemical composition of the Earth: Enstatite chondrite models. Earth Planet. Sci. Lett., 293(3-4):259 - 268, 2010. doi: 0.1016/j.epsl.2010.02.033.

R. Jeanloz and S. Morris. Is the mantle geotherm sub-adiabatic? Geophys. Res. Lett., 143:335-338, 1987.

A. M. Jellinek and M. Manga. The influence of a chemical boundary layer on the fixity, spacing and lifetime of mantle plumes. Nature, 418:760-763, 2002. doi: 10.1038/nature00979.

S.-I. Karato. The importance of anelasticity in the interpretation of seismic tomography. Geophys. Res. Lett., 20:1623 - 1626, 1993.

S.-I. Karato. Deformation of Earth materials: an introduction to the rheology of solid Earth. Cambridge University Press, 2008.

S.-I. Karato and B. B. Karki. Origin of lateral variation of seismic wave velocities and density in the deep mantle. J. Geophys. Res., 106:21771-21783, 2001.

L. H. Kellogg, B. H. Hager, and R. D. van der Hilst. Compositional stratification in the deep mantle. Science, 283:1881-1884, 1999. doi: 10.1126/science.283.5409.1881.

B. L. N. Kennett, R. Engdahl, and R. Buland. Constraints on seismic velocities in the Earth from traveltimes. Geophys. J. Int., 122:108-124, 1995. doi: 10.1111/j.1365-246X.1995.tb03540.x.

B. L. N. Kennett, S. Widiyantoro, and R. D. van der Hilst. Joint seismic tomography for bulk sound and shear wave speed in the Earth's mantle. J. Geophys. Res., 103:12469-12493, 1998.

A. Khan, J. A. D. Connolly, and S. R. Taylor. Inversion of seismic and geodetic data for the major element chemistry and temperature of the Earth's mantle. J. Geophys. Res., 113:B09308, 2008. doi: 10.1029/2007JB005239.

S. Labrosse, J. W. Hernlund, and N. Coltice. A crystallizing dense magma ocean at the base of Earth's mantle. Nature, 450:866-869, 2007. doi: 10.1038/nature06355. 
T. Lay, J. Hernlund, and B. A. Buffett. Core-mantle-boundary heat flow. Nature Geo., 1:25-32, 2008. doi: 10.1038/ngeo.2007.44.

W. Leng and S. Zhong. Controls on plume heat flux and plume excess temperature. J Geophys. Res., 113, 2008. doi: 10.1029/2007JB005155.

C. Li, R. D. van der Hilst, E. R. Engdahl, and S. Burdick. A new global model for P-wave speed variations in Earth's mantle. Geochem. Geophys. Geosys., 5, 2008. doi: 10.1029/2007GC001806.

T. Lyubetskaya and J. Korenaga. Chemical composition of Earth's primitive mantle and its variance: 2. implications for global geodynamics. J. Geophys. Res., 112:B03212, 2007. doi: 10.1029/2005JB004224.

A. E. Malcolm and J. Trampert. Tomographic errors from wave front healing: more than just a fast bias. Geophys. J. Int, 185:385-402, 2011. doi: 10.1111/j.1365-246X.2011.04945.x.

G. Masters and D. Gubbins. On the resolution of density within the Earth. Phys. Earth Planet. Int., 140: 159-167, 2003.

G. Masters, G. Laske, H. Bolton, and A. M. Dziewonski. The relative behavior of shear velocity, bulk sound speed, and compressional velocity in the mantle: implications for chemical and thermal structure. $A G U$ Monograph, Earth's Deep Interior, 171:63-87, 2000.

J. Matas and M. S. T. Bukowinski. On the anelastic contribution to the temperature dependence of lower mantle seismic velocities. Earth Planet. Sci. Lett., 259:51-65, 2007. doi: 10.1016/j.epsl.2007.04.028.

J. Matas, J. Bass, Y. Ricard, E. Mattern, and M. S. T. Bukowinski. On the bulk composition of the lower mantle: predictions and limitations from generalized inversion of radial seismic profiles. Geophys. J. Int, 170:764-780, 2007. doi: 10.1111/j.1365-246X.2007.03454.x.

W. F. McDonough and S.-S. Sun. The composition of the Earth. Chem. Geol., 120:223-253, 1995.

A. K. McNamara and S. Zhong. Thermo-chemical structures within a spherical mantle. J. Geophys. Res., 109:B07402, 2004. doi: 10.1029/2003JB002847.

A. K. McNamara and S. Zhong. Thermo-chemical structures beneath Africa and the Pacific Ocean. Nature, 437:1136-1139, 2005. doi: 10.1038/nature04066.

R. Montelli, G. Nolet, G. Masters, F. A. Dahlen, and S.-H. Hung. Global P and PP traveltime tomography: rays versus waves. Geophys. J. Int, 158:630-654, 2004.

I. Mosca, L. Cobden, A. Deuss, J. Ritsema, and J. Trampert. Seismic and mineralogical structures of the lower mantle from probabilistic tomography. J. Geophys. Res., 117:B06304, 2012. doi: 10.1029/2011JB008851.

T. Nakagawa and P. J. Tackley. Effects of a perovskite-post perovskite phase change near coremantle-boundary in compressible mantle convection. Geophys. Res. Lett., 31:L16611, 2004. doi: 10.1029/2004GL020648.

T. Nakagawa, P. J. Tackley, F. Deschamps, and J. A. D. Connolly. The influence of MORB and Harzburgite composition on thermo-chemical mantle convection in a 3D spherical shell with self-consistently calculated mineral physics. Earth Planet. Sci. Lett., 296:403-412, 2010. doi: 10.1016/j.epsl.2010.05.026.

S. D. Ni, E. Tan, M. Gurnis, and D. V. Helmberger. Sharp sides to the African superplume. Science, 296: 1850-1852, 2002. doi: 10.1126/science.1070698. 
P. Olson, R. Deguen, L. A. Hinnov, and S.J. Zhong. Controls on geomagnetic reversals and core evolution by mantle convection in the phanerozoic. Phys. Earth Planet. Int., 214:87 - 103, 2013. doi: 10.1016/j.pepi.2012.10.003.

S. Ranalli. Rheology of the Earth. Chapman \& Hall (London and New York), 1995.

R. P. Rapp, T. Irifune, N. Shimizu, N. Nishiyama, M. D. Norman, and T. Inoue. Subduction recycling of continental sediments and the origin of geochemically enriched reservoirs in the deep mantle. Earth Planet. Sci. Lett., 271:14-23, 2008. doi: 10.1016/j.epsl.2008.02.028.

Y. Ricard, M. A. Richards, C. Lithgow-Bertelloni, and Y. LeStunff. A geodynamic model of mantle mass heterogeneities. J. Geophys. Res., 98:21895-21909, 1993.

Y. Ricard, F. Chambat, and C. Lithgow-Bertelloni. Gravity observations and 3-D structure of the Earth. C. R. Geosci, 338:992-1001, 2006.

M. A. Richards and D. C. Engebretson. Large-scale mantle convection and the history of subduction. Nature, 355:437-440, 1992. doi: 10.1029/2007JB005155.

J. Ritsema and H. J. van Heijst. Constraints on the correlation of P- and S-wave velocity heterogeneity in the mantle from P, PP, PPP and PKPab traveltimes. Geophys. J. Int, 149:482-489, 2002. doi: 10.1046/j.1365-246X.2002.01631.x.

J. Ritsema, S. Ni, D. V. Helmberger, and H. P. Crotwell. Evidence for strong shear velocity reductions and velocity gradients in the lower mantle beneath Africa. Geophys. Res. Lett., 25:4245-4248, 1998.

J. Ritsema, A. K. McNamara, and A. Bull. Tomographic filtering of geodynamic models: implications for model interpretation and large-scale mantle structure. J. Geophys. Res., 112, 2007. doi: 10.1029/2006JB004566.

J. Ritsema, H. J. van Heijst, A. Deuss, and J. H. Woodhouse. S40RTS: a Degree-40 shear velocity model for the mantle from new Rayleigh wave dispersion, teleseismic traveltimes, and normal-mode splitting function measurements. Geophys. J. Int., 184:1223-1236, 2011. doi: 10.1111/j.1365-246X.2010.04884.x.

G. S. Robertson and J. H. Woodhouse. Evidence for proportionality of P and S heterogeneity in the lower mantle. Geophys. J. Int., 123:85-116, 1995.

B. Romanowicz. Can we resolve 3-D density heterogeneity in the lower mantle? Geophys. Res. Lett., 28: 1107-1110, 2001.

R. L. Saltzer, R. D. van der Hilst, and H. Karason. Comparing P and S wave heterogeneity in the mantle. Geophys. Res. Lett., 28:1335-1338, 2001.

N. Schaeffer and M. Manga. Interaction of rising and sinking mantle plumes. Geophys. Res. Lett., 28: $455-458,2001$.

B. S. A. Schuberth, H.-P. Bunge, and J. Ritsema. Tomographic filtering of high-resolution mantle circulation models: can seismic heterogeneity be explained by temperature alone? Geochem. Geophys. Geosyst., 10: Q05W03, 2009a. doi: 10.1029/2009GC002401.

B. S. A. Schuberth, H.-P. Bunge, G. Steinle-Neumann, C. Moder, and J. Oeser. Thermal versus elastic heterogeneity in high-resolution mantle circulation models with pyrolite composition: high plume excess temperatures in the lowermost mantle. Geochem. Geophy. Geosyst., 10:Q01W01, 2009b. doi: 10.1029/2008GC002235. 
B. S. A. Schuberth, C. Zaroli, and G. Nolet. Synthetic seismograms for a synthetic Earth: long-period Pand S-wave traveltime variations can be explained by temperature alone. Geophys. J. Int., 200:1393-1412, 2012. doi: 10.1111/j.1365-246X.2011.05333.x.

G. E. Shephard, H.-P. Bunge, B. S. A. Schuberth, R. D. Muller, A. S. Talsma, C. Moder, and T. C. W. Landgrebe. Testing absolute plate reference frames and the implications for the generation of geodynamic mantle heterogeneity structure. Earth Planet. Sci. Lett., 317:204-217, 2012. doi: 10.1016/j.epsl.2011.11.027.

N. A. Simmons, A. M. Forte, L. Boschi, and S. P. Grand. GyPSuM: a joint tomographic model of mantle density and seismic wave speeds. J. Geophys. Res., 115, 2010. doi: 10.1029/2010JB007631.

N. A. Simmons, S. C. Myers, and G. Johannesson. Global-scale p wave tomography optimized for prediction of teleseismic and regional travel times for middle east events: 2. tomographic inversion. J. Geophys. Res., 116:B04305, 2011. doi: 10.1029/2010JB007969.

O. Sramek, W. F. McDonough, E. S. Kite, V. Lekic, S. T. Dye, and S. Zhong. Geophysical and geochemical constraints on geoneutrino fluxes from Earth's mantle. Earth Planet. Sci. Lett., 361:356-366, 2013.

G. M. Stampfli and G. D. Borel. A plate tectonic model for the Paleozoic and Mesozoic constrained by dynamic plate boundaries and restored synthetic oceanic isochrons. Earth Planet. Sci. Lett., 196:17-33, 2002 .

G. M. Stampfli and C. Hochard. Plate tectonics of the Alpine realm. Geol. Soc. London, Special Publications, 327:89-111, 2009.

D. R. Stegman, A. M. Jellinek, S. A. Zatman, J. R. Baumgardner, and M. A. Richards. An early lunar core dynamo driven by thermo-chemical mantle convection. Nature, 421:143-146, 2003.

B. Steinberger. Plumes in a convecting mantle: Models and observations for individual hotspots. J. Geophys. Res., 105:11127-11152, 2000.

B. Steinberger and T. H. Torsvik. A geodynamic model of plumes from the margins of large low shear velocity provinces. Geochem. Geophys. Geosys., 13:Q01W09, 2012. doi: 10.1029/2011GC003808.

L. Stixrude and C. Lithgow-Bertelloni. Thermodynamics of mantle minerals - i. physical properties. Geophys. J. Int., 162:610-632, 2005. doi: 10.1111/j.1365-246X.2005.02642.x.

L. Stixrude and C. Lithgow-Bertelloni. Influence of phase transformations on lateral heterogeneity and dynamics in Earth's mantle. Earth Planet. Sci. Lett, 263:45-55, 2007. doi: 10.1016/j.epsl.2007.08.027.

L. Stixrude and C. Lithgow-Bertelloni. Thermodynamics of mantle minerals - ii. phase equilibria. Geophys. J. Int., 184:1180-1213, 2011. doi: 10.1111/j.1365-246X.2010.04890.x.

E. Styles, D. R. Davies, and S. Goes. Mapping spherical seismic into physical structure: biases from 3-D phase-transition and thermal boundary-layer heterogeneity. Geophys. J. Int., 184:1371-1378, 2011. doi: 10.1111/j.1365-246X.2010.04914.x.

W. J. Su and A. M. Dziewonski. Simultaneous inversion for 3-D variations in shear and bulk velocity in the mantle. Phys. Earth Planet. Int., 100:135-156, 1997.

P. J. Tackley. Three-dimensional simulation of mantle convection with a thermo-chemical boundary layer: D"? In M. Gurnis and M. E. Wysession and E. Knittle and B. A. Buffet (Eds.), The core-mantle-boundary region, pages 231-253. AGU, Washington DC, 1998. 
P. J. Tackley. Strong heterogeneity caused by deep mantle layering. Geochem. Geophys. Geosys., 3:1024, 2002. doi: $10.1029 / 2001 \mathrm{GC} 000167$.

P. J. Tackley. Mantle geochemical geodynamics. In Treatise on Geophysics, Vol. 7: Mantle Dynamics, pages 437-505. Elsevier, 2007.

P. J. Tackley and S. D. King. Testing the tracer ratio method for modelling active compositional fields in mantle convection simulations. Geochem. Geophys. Geosys, 4:8302, 2003. doi: 10.1029/2001GC000214.

P. J. Tackley, S. Xie, T. Nakagawa, and J. W. Hernlund. Numerical and laboratory studies of mantle convection: philosophy, accomplishments and thermo-chemical structure and evolution. In Earth's Deep Mantle: Structure, Composition, and Evolution, Geophysical Monograph Series, 160, pages 83-99. AGU, Washington DC, 2005. doi: 10.1029/1160GM1007.

E. Tan, M. Gurnis, and L. J. Han. Slabs in the lower mantle and their modulation of plume formation. Geochem. Geophys. Geosys., 3:1067, 2002. doi: 10.1029/2001GC000238.

E. Tan, W. Leng, S. Zhong, and M. Gurins. On the location of plumes and mobility of thermo-chemical structures with high bulk modulus in the 3-D compressible mantle. Geochem. Geophys. Geosys., 12: Q07005, 2011. doi: 10.1029/2011GC003665.

M. S. Thorne, E. J. Garnero, and S. P. Grand. Geographic correlation between hotspots and deep mantle lateral shear-wave velocity gradients. Phys. Earth Planet. Int., 146:47-63, 2004. doi: 10.1016/j.pepi.2003.09.026.

A. To, B. Romanowicz, Y. Capdeville, and N. Takeuchi. 3-D effects of sharp boundaries at the borders of the African and Pacific superplumes: observation and modeling. Earth Planet. Sci. Lett., 233:137-153, 2005. doi: $10.1016 /$ j.epsl.2005.01.037.

T. H. Torsvik, M. A. Smethurst, K. Burke, and B. Steinberger. Large igneous provinces generated from the margins of the large low-velocity provinces in the deep mantle. Geophys. J. Int., 167:1447-1460, 2006. doi: 10.1111/j.1365-246X.2006.03158.x.

T. H. Torsvik, R. D. Muller, R. van der Voo, B. Steinberger, and C. Gaina. Global plate motion frames: towards a unified model. Rev. Geophys., 46:1-44, 2008a. doi: 10.1029/2007RG000227.

T. H. Torsvik, M. A. Smethurst, K. Burke, and B. Steinberger. Long term stability in deep mantle structure: Evidence from the $\sim 300 \mathrm{Ma}$ Skagerrak-Centered Large Igneous Province (the SCLIP). Earth Planet. Sci. Lett., 267:444-452, 2008b. doi: 10.1016/j.epsl.2007.12.004.

T. H. Torsvik, K. Burke, B. Steinberger, S. J. Webb, and L. D. Ashwal. Diamonds sampled by plumes from the core-mantle-boundary. Nature, 466:352-358, 2010. doi: 10.1038/nature09216.

N. Tosi, D. A. Yuen, and O. Cadek. Dynamical consequences in the lower mantle with the post-perovskite phase change and strongly depth-dependent thermodynamic and transport properties. Earth Planet. Sci. Lett., 298:229-243, 2010. doi: 10.1016/j.epsl.2010.08.001.

J. Trampert, P. Vacher, and N. Vlaar. Sensitivities of seismic velocities to temperature, pressure and composition in the lower mantle. Phys. Earth Planet. Int., 124:255-267, 2001. doi: 10.1016/S00319201(01)00201-1.

J. Trampert, F. Deschamps, J. Resovsky, and D. Yuen. Probabilistic tomography maps chemical heterogeneities throughout the lower mantle. Science, 306:853-856, 2004. doi: 10.1126/science.1101996. 
M. Trieloff, J. Kunz, D. A. Clague, D. Harrison, and C. J. Allègre. The nature of pristine noble gases in mantle plumes. Science, 288:1036-1038, 2000. doi: 10.1126/science.288.5468.1036.

R. D. van der Hilst, S. Widiyantoro, and E. R. Engdahl. Evidence for deep mantle circulation from global tomography. Nature, 386:578-584, 1997. doi: 10.1038/386578a0.

R. D. van der Hilst, M. V. de Hoop, P. Wang, S. H. Shim, P. Ma, and L. Tenorio. Seismostratigraphy and thermal structure of Earth's core-mantle-boundary region. Science, 315:1813-1817, 2007. doi: 10.1126/science.1137867.

M.J. Walter, E. Nakamura, R.G. Tronnes, and D.J. Frost. Experimental constraints on crystallisation differentiation in a deep magma ocean. Geochim. Cosmo. Acta, 68:4267-4284, 2004. doi: 10.1016/j.gca.2004.03.014.

Y. Wang and L. Wen. Mapping the geometry and geographic distribution of a very-low velocity province at the base of the Earth's mantle. J. Geophys. Res., 109:B10305, 2004. doi: 110.1029/2003 JB002674.

Y. Wang and L. Wen. Geometry and P and S velocity structure of the 'African anomaly'. J. Geophys. Res., 112, 2007. doi: 10.1029/2006JB004483.

G. J. Wasserburg and D. J. De Paolo. Models of Earth structure inferred from Neodymium and Strontium isotopic abundances. Proc. Natl. Acad. Sci. USA, 76:3594-3598, 1979.

J. Woodhouse and A. Dziewonski. Seismic modeling of the Earth's large scale 3-D structure. Phil. Trans. Roy. Soc., 328:291, 1989. doi: 10.1098/rsta.1989.0037.

J. Wookey, S. Stackhouse, J.-M. Kendall, J. Brodholt, and G. D. Price. Efficacy of the post-perovskite phase as an explanation for lowermost-mantle seismic properties. Nature, 438:1004-1007, 2005. doi: 10.1038/nature04345.

S. Xie and P. J. Tackley. Evolution of Helium and Argon isotopes in a convecting mantle. Phys. Earth Planet. Int., 146:417-439, 2004.

W. Xu, C. Lithgow-Bertelloni, L. Stixrude, and J. Ritsema. The effect of bulk composition and temperature on mantle seismic structure. Earth Planet. Sci. Lett., 275:70-79, 2008.

N. Zhang and S. J. Zhong. Heat fluxes at the earth's surface and coremantle boundary since pangea formation and their implications for the geomagnetic superchrons. Earth Planet. Sci. Lett., 306:205-216, 2011. doi: 10.1016/j.epsl.2011.04.001.

N. Zhang, S. J. Zhong, W. Leng, and Z. X. Li. A model for the evolution of Earth's mantle structure structure since the early Paleozoic. J. Geophys. Res., 115:B06401, 2010. doi: 10.1029/2009JB006896.

D. Zhao and J. Lei. Seismic ray path variations in a 3D global velocity model. Phys. Earth Planet. Int., 141:153-166, 2003. doi: 10.1016/j.pepi.2003.11.010.

A. Zindler and S. Hart. Chemical geodynamics. Ann. Rev. Earth Planet. Sci., 14:493-571, 1986. doi: 10.1146/annurev.ea.14.050186.002425. 